\title{
Signaling and Counter-Signaling in the Judicial Hierarchy: An Empirical Analysis of En Banc Review
}

\author{
Deborah Beim* \\ Yale University \\ deborah.beim@yale.edu \\ Alexander V. Hirsch \\ California Institute of Technology \\ avhirsch@hss.caltech.edu \\ Jonathan P. Kastellec \\ Princeton University \\ jkastell@princeton.edu
}

January 19, 2015

\begin{abstract}
We leverage the institutional features of American courts to evaluate the importance of whistleblowers in hierarchical oversight. Drawing on a formal theory of signaling in the judicial hierarchy, we examine the role of whistleblowing dissents in triggering en banc review of three-judge panels by full circuits of the Courts of Appeals. The theory generates predictions about how dissent interacts with judicial preferences to influence circuits' review and reversal decisions, which we test using original and existing data. First, we show that judges who dissent counter to their preferences are more likely to see their dissents lead to review and reversal. Second, we show that dissents are most influential when the likelihood of non-compliance by a three-judge panel is highest. Our results underscore the importance of dissent in the judicial hierarchy and illustrate how judicial whistleblowers can help appellate courts target the most important cases for review.
\end{abstract}

${ }^{*}$ We thank Tom Clark and Stefanie Lindquist for generously sharing data with us. We thank Alex Acs, Chuck Cameron, Tom Clark, Paul Collins, Greg Huber, Lewis Kornhauser, Chris Zorn, and seminar participants at Yale and Penn State for helpful comments and suggestions. 


\section{Introduction}

When responsibility is delegated in a hierarchical organization, an agent has the opportunity to take actions that a superior might dislike. In large hierarchies, this can be a problem: subordinates take so many actions that it is simply not feasible for a principal to review most of them. One way to mitigate this difficulty is to promote the use of whistleblowers. A wideranging theoretical literature has documented how whistleblowers can inform superiors of possible non-compliance or mismanagement by an agent (see e.g. McCubbins and Schwartz 1984, Lupia and McCubbins 1994, Epstein and O'Halloran 1995, Austen-Smith and Feddersen 2008, Ting 2008, Gailmard and Patty 2013). But empirical tests of such theories are few - in part, because in many contexts it is difficult to identify the regular interactions of principals, agents, and whistleblowers. As a result, we know little about how whistleblowers can systematically assist principals in their oversight of agents.

In this paper we leverage the institutional features of the federal judicial hierarchy to evaluate this question. We examine the hierarchical relationship that exists within the U.S. Courts of Appeals. Cases in these courts are heard by panels of three judges, who are randomly chosen among the judges of a given circuit. A judge who disagrees with the decision of her colleagues may publicly signal her disagreement with a written dissent. Following a panel's decision, a majority of active judges on a circuit can vote to rehear a case en banc, thereby engaging in discretionary review. However, such reviews are both rare and costly, and occur in only about $1 \%$ of cases. Thus, the Courts of Appeals' need for high quality information when deciding which cases to review provides the opportunity for lower court

judges to act as whistleblowers through their strategic use of dissent. We examine how such whistleblowing dissents affect the likelihood that a full circuit will review a panel's decision, and, conditional on review, whether the circuit will reverse a panel's decision.

Research on discretionary case selection by both the Supreme Court and the Courts of Appeals has demonstrated that cases with dissent are much more likely to be reviewed than cases without. However, the possibility that the influence of dissents varies across particular 
types of dissents - in terms of both the signal they send to a higher court and the type of judge sending such a signal-has received less attention. To generate precise theoretical predictions about the relationship between judicial whistleblowers, dissents, and en banc review, we use the formal theory developed in Beim, Hirsch and Kastellec (2014), which examines how both the possibility and actuality of dissent influence interactions between the members of a lower court and a higher court with a discretionary docket. For ease of presentation, we call this the "whistleblower theory." 1 While the whistleblower theory is general, it nicely captures the dynamics of a full circuit deciding whether to review a threejudge panel's decision. In particular, the theory offers several predictions about how the presence or absence of a dissent will interact with preferences in the hierarchy to influence the decision to both review and reverse a panel's decision. These predictions are new to both the literatures on en banc review and on the judicial hierarchy more generally.

We test these predictions using a combination of existing and original data on Courts of Appeals cases decided from 1986 to 2002. This data includes the universe of three-judge panel decisions in which a full circuit voted to rehear that decision en banc, plus a random sample of cases not reheard. With this data in hand, we use measures of judicial ideology to define a whistleblower on a panel, who may or may not dissent. This allows us to distinguish between dissents that the theory identifies as intended to signal non-compliance, which we term whistleblowing dissents, and other types of dissent.

We first examine how the preferences of whistleblowers affect the probability of review. The whistleblower theory predicts that whistleblowers who are ideologically closer to the panel majority -i.e. "allies" of the majority - are more credible messengers about severe non-compliance by that majority. Conversely, according to the theory, whistleblowers who are ideologically distant from the panel majority are less credible because they are too willing to dissent when they disagree with the panel majority's decision, even in cases where

\footnotetext{
${ }^{1}$ Whistleblower theory applied to the judicial hierarchy originated with Cross and Tiller (1998), and has been extended in several theoretical and empirical applications (see e.g. Sunstein et al. 2006, Kastellec 2007, Kim 2008, Beim and Kastellec 2014, inter alia). The specific theory of whistleblowing in Beim, Hirsch and Kastellec (2014) that we apply should be distinguished from this more general line of inquiry.
} 
noncompliance is less severe. We call this combination of preferences and dissenting behavior counter-preference signaling - sending signals that run counter to one's preferences. We find that counter-preference signals are an important predictor of en banc review: moving from a whistleblowing dissent written by a judge whose ideology is very distant from the panel majority to one who is very close raises the probability of en banc review from $3 \%$ to $17 \%$.

We next examine how the effect of a whistleblowing dissent on review is mediated by the degree of preference divergence between the panel and the full circuit that oversees it. The whistleblower theory predicts that whistleblowing dissents should be most effective at triggering review when the panel and full circuit are ideologically distant. The reason for this effect is intuitive: ceteris paribus, dissent is a stronger signal of severe non-compliance when the potential for noncompliance is greater. We find that this distance is also an important mediator of the effect of dissent on en banc review: the marginal effect of a whistleblowing dissent is about 46 percentage points when panels and full circuits are distant, compared to about three percentage points when they are close. Both this and the effect of counterpreference signals are quite striking, given the overall rarity of en banc review.

Finally, the whistleblower theory generates several predictions about the likelihood that the full circuit reverses a decision by a three-judge panel, conditional on review. First, the theory predicts that in unanimous cases, the likelihood of reversal decreases both as a panel and the potential whistleblower move toward the full circuit. We find strong evidence for the former and weak evidence for the latter. The effect of panel-circuit distance is sizable: a reviewed unanimous decision by a panel most distant from the full circuit is 30 percentage points more likely to be reversed than one by a panel closest to the full circuit. Second, the whistleblower theory predicts, and the data show, that reviewed cases with whistleblowing dissents are more likely to be reversed than reviewed unanimous decisions. Taken together, these results have important implications for assessing the role of whistleblowers in the judicial hierarchy, and suggest ways forward for understanding whistleblowing more broadly in other institutional contexts. 


\section{Whistleblowing, Dissents, and Discretionary Review}

The relationship between dissent and discretionary review in the judicial hierarchy has a long lineage in judicial politics (see e.g. Tanenhaus et al. 1963, Perry 1991). Why are nonunanimous cases more likely to be reviewed by higher courts? For one, dissents may indicate that a case is more controversial, important, or difficult. A dissent may also explicitly indicate that the majority made a decision contrary to precedent or a higher court's preferences.

In evaluating the informational role of dissent at different levels of the judiciary, it is useful to distinguish between the core functions of the en banc process and the Supreme Court's certiorari process. Whereas the Supreme Court does not usually engage in error correction (focusing almost solely on law creation and rule modification), the en banc process is designed to function in large part as an error-correction institution, where errors may be understood as either technical mistakes, or failures to comply with the preferences of higher courts (George 1999). Thus, en banc review is more likely to focus on weeding out noncompliance by three-judge panels than the certiorari process (Oliphant 1991, Note 1989, Banks 1999).

Formally, en banc review allows the full circuit to re-hear a case after a three-judge panel has decided it. Litigants may petition for en banc review; any judge on the circuit-including both those on the three-judge panel and those not on the panel-may also suggest to his colleagues that they review a decision en banc. The active judges on the circuit then vote, by majority rule, on whether to take the case. Since whistleblowing is fundamentally about exposing non-compliance, dissents that serve a whistleblowing function are more likely to be influential in en banc review, compared to Supreme Court review. Indeed, the weight of evidence suggests that judges on the Courts of Appeals strategically use dissents - in certain situations - to signal to full circuits that a panel majority's decision is worthy of review. ${ }^{2}$ Moreover, Kim (2008) and Kastellec (2011) find that the voting behavior of panels of the

\footnotetext{
${ }^{2}$ In a recent and comprehensive study, Blackstone and Collins Jr (2014) reach this conclusion, supporting similar findings by Van Winkle (1997) and Kim (2008). These papers stand against the findings of Hettinger, Lindquist and Martinek $(2004 ; 2006)$, who found no evidence of strategic dissents.
} 
Courts of Appeals is conditioned by the panel's relationship to the full circuit.

Accordingly, when thinking about the relationship between dissents and discretionary review, we can place dissents into two broad categories. We can think of one category of dissents as "whistleblowing dissents" that are intended by a judge to signal non-compliance to a higher court (Cross and Tiller 1998). "Non-whistleblowing dissents" are all other types of dissents, including "expressive" dissents in which a judge's goal is solely to voice disagreement with a decision by a panel majority. (We elaborate more on this distinction below.) Most studies of en banc review, however, have pooled all dissents together (see e.g. George 1999, Clark 2009). While these studies have convincingly shown a substantial additive effect of dissent on en banc review, they do not allow this effect to differ across judges (or dispositions).

Two exceptions are noteworthy. First, Giles, Walker and Zorn (2006) find that while dissents increase the probability of en banc review, there is no additional effect of dissent in cases decided against the preferences of a circuit majority. Beim and Kastellec (2014), however, find that more conservative circuits are more likely to review liberal decisions with dissent than conservative decisions with dissent, while liberal circuits are more likely to review conservative decisions with dissent than liberal decisions with dissent. However, while both of these studies allow the effect of dissents to differ across dispositions (or case outcomes), neither allows the effect to differ across the ideology of the dissenting judge.

In addition, among the many studies of discretionary review (including both en banc and certiorari on the Supreme Court), there has been little research connecting the review decision with the decision whether to reverse. This is surprising, because the theoretical models explaining case selection necessarily have implications for the likelihood of reversal, conditional on review. ${ }^{3}$ For example, the seminal formal theory of certiorari developed in Cameron, Segal and Songer (2000) predicts which cases should be reversed, yet only the model's predictions with respect to review are tested.

\footnotetext{
${ }^{3}$ Carrubba and Clark (2012) and Hall (2009) both study how the distance between lower courts and the Supreme Court conditions the likelihood of review and reversal. These articles, however, treat dissent simply as a control variable.
} 


\subsection{Counter-preference signals and dissents}

In developing predictions about which types of whistleblowers might be most likely to trigger en banc review, this paper relates to a large literature showing how biased information may be more useful than unbiased information (Calvert 1985). Given preference divergence between two actors in a signaling framework, a signal that is biased against a sender's preferences will have more credibility than one that is biased toward them. Thus, in some instances, actors who must infer the meaning of signals under conditions of imperfect information may prefer to have biased senders. For exposition, we call signals sent by biased actors "counter-preference signals" — those that run counter to one's preferences.

The logic of this argument is nicely illustrated in a recent study of the influence of newspaper endorsements by Chiang and Knight (2011). They find that the interaction between the predisposition of a newspaper and the ideological direction of an endorsement determines how strongly that endorsement will influence vote choice among readers. If a left-leaning paper endorses a Republican candidate, Democratic voters are more likely vote for that candidate, and vice versa.

Similarly, the value of biased information has been demonstrated in research on discretionary review in the judicial hierarchy. In the formal theory presented in Cameron, Segal and Songer (2000), a higher court that is uncertain about the compliance of a lower court can infer that the lower court complied if the decision is biased against the lower court, given the relative preferences of the two courts. Cameron et al. call this the Nixon goes to China result - "if a cold warrior like Nixon goes to China it must be time for a change in American policy." The logic of this result has been extended to the study of en banc review by Giles, Walker and Zorn (2006) and Clark (2009). Both articles find that full circuits are most likely to review decisions by ideologically distant panels that likely do not conform with the

preferences of the full circuit - that is, decisions that do not run counter to the relative preference of the three-judge panel. No study, however, has examined how counter-preference signals from dissenters (or potential dissenters) may also provide information to a full cir- 
cuit deciding whether to review a case. Are certain dissenters more credible messengers of non-compliance than others? If so, why?

\section{Theory and Hypotheses}

To generate theoretical predictions about signals and counter-preference signals in the judicial hierarchy, we use the whistleblower theory developed in Beim, Hirsch and Kastellec (2014). The theory models dissent as motivated by the desire of a lower court judge to blow the whistle on her colleagues about non-compliance with a higher court's preferences, in order to trigger review and reversal. Other plausible motives for dissent are outside the model, although we account for some of these in the empirical analysis.

In the theory, a lower court hears a case in the shadow of potential review and reversal by a higher court. The judge whose preferences are most aligned with the higher court can be thought of as a potential whistleblower, in that she can choose to report non-compliance by her colleagues through a whistleblowing dissent, which can potentially trigger a review and reversal. Alternatively, she can choose not to dissent, creating a unanimous decision. For ease of presentation, we henceforth refer to the potential whistleblower as simply the whistleblower, with the understanding that this label describes her potential to act as a whistleblower, but not always her actual behavior. This distinction is important because both the presence and absence of a dissent by the whistleblower are informative to the higher court.

In our empirical application we treat the median of the three-judge panel as the lower court majority, and the median of the full circuit as the higher court. Accordingly, we refer to the lower court as the panel (or panel majority) and the higher court as the full circuit (or simply circuit) from this point forward.

In the theory, cases exist on a continuum according to the facts of the case (e.g. the intensity of a search in a Fourth Amendment case). For a given case, the panel makes a binary decision that the case should receive the "liberal" or "conservative" outcome. Initially these case facts are known only to the panel judges, but the full circuit can make inferences 
about them based on the panel judges' actions. After making these inferences, the circuit can then choose to review the panel's decision (at some cost), at which point it learns the true facts of the case, and can reverse or affirm the decision. If the circuit reverses the panel, then the judges in the panel majority suffer a sanctioning cost.

Each judge's preferences over dispositions given a set of case facts are modeled as an indifference point, which can fall anywhere on the continuum of case facts. A judge prefers that cases to the right of his indifference point be decided liberally, and cases to the left of his indifference point be decided conservatively. Importantly, judges care more about the disposition of some cases than others; the further a case falls from a judge's indifference point, the more intensely he cares about getting the "correct" outcome. Thus, the circuit will care more about "severe" non-compliance - the panel ruling liberally in cases that are far to the left of the circuit's indifference point - than less-severe non-compliance.

Figure 1 depicts preferences and actions in the theory when the panel is more liberal than the circuit (we maintain this assumption throughout the presentation of the theory, although our empirical analysis accounts for all possible configurations of judges). The indifference points of the panel and the circuit are depicted with solid circles (we discuss the location of the whistleblower below). Given these preferences, there exists a "conflict region" between the panel and the full circuit. In cases in this region, the panel prefers to rule liberally, but the circuit would instead prefer a conservative ruling. The panel must decide whether or not to issue a non-compliant liberal ruling in the shadow of a potential threat by the whistleblower to dissent, and the review and reversal that dissent may trigger.

In the equilibrium of the model, the behavior of the panel majority is governed by a cutpoint, depicted with a solid vertical line in in Figure 1. It chooses the conservative ruling when the case facts fall below this cutpoint (Region 1), and chooses the liberal ruling when the case facts fall above it (Regions 2-4). In the theory, the full circuit always agrees with the disposition when the panel would rule conservatively, because the panel is more liberal than the circuit. A conservative decision by the panel is thus a perfect signal of compliance, 


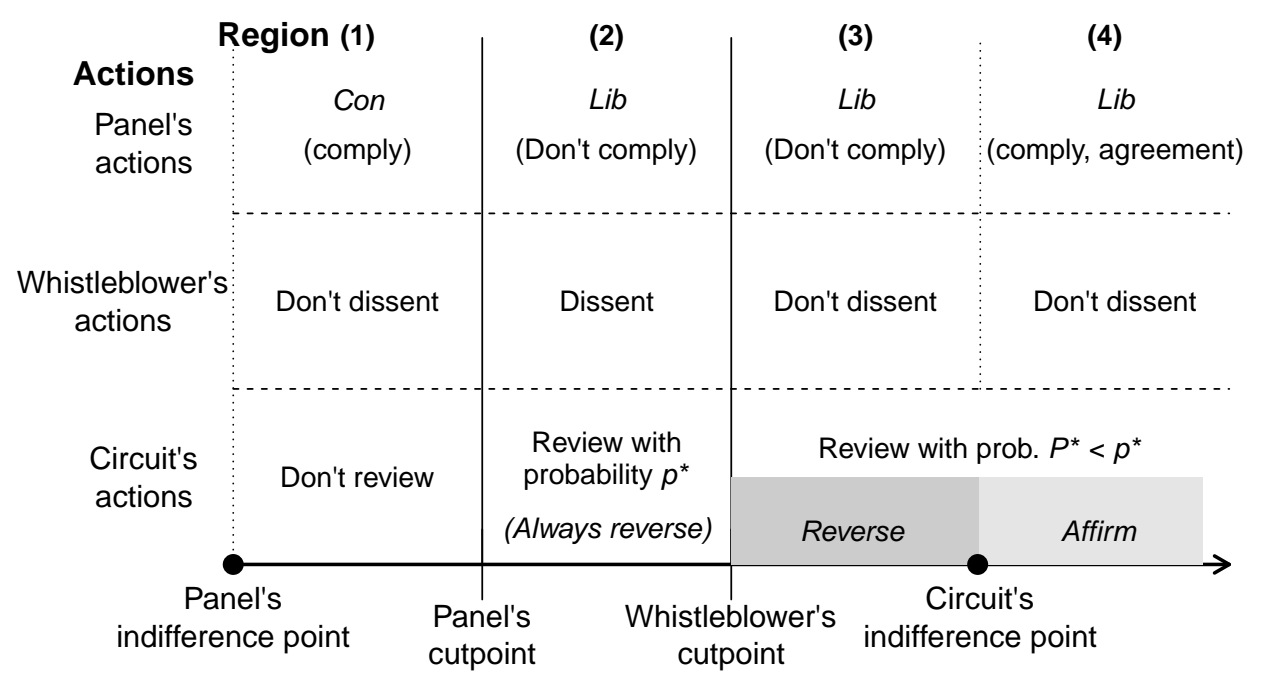

Figure 1: Summary of theory. See text for details

and we therefore label it as non-suspicious. In the theory, non-suspicious decisions are never reviewed, nor reversed. In addition, because the whistleblower in the theory is assumed to be solely motivated by her desire to trigger reversal, she also never makes a costly and fruitless dissent from such rulings.

In contrast, a liberal decision may or may not be compliant. Sometimes the case facts are in the conflict region, and the panel prefers the liberal disposition when the circuit does not (Regions 2-3). Other times, both courts prefer a liberal decision (Region 4). Since the circuit cannot observe case facts without reviewing, from its perspective compliant liberal rulings are pooled with non-compliant ones. We therefore term such rulings suspicious, because upon observing them the circuit is uncertain about whether non-compliance occurred.

This uncertainty presents an opportunity for the whistleblower to provide additional information through a dissent. Like the panel majority, the whistleblower's behavior is governed by a cutpoint, which describes when she dissents from a suspicious liberal ruling by her colleagues. Figure 1 depicts the behavior of a whistleblower who is more conservative than the panel majority (the whistleblower can be either less or more conservative than the circuit). Such a whistleblower will pay the cost of dissent only if both noncompliance occurred (since there is no point in triggering a review of a compliant ruling), and the case facts are sufficiently far from his indifference point to make the chance of triggering reversal worthwhile (Region 2). Consequently, when the circuit observes a whistleblowing dissent, it 
is certain that non-compliance occurred, but uncertain about exactly how severe that noncompliance was. It will therefore only sometimes review the case (if it is worth the time), but always reverse upon review. Crucially for our empirical tests, how likely the circuit is to review after a whistleblowing dissent depends on the credibility of the judge issuing it. As we detail below, some whistleblowers will be more credible messengers of severe non-compliance than others, and therefore be more effective at triggering review and reversal.

Finally, there are some non-compliant cases in which the whistleblower disagrees with the panel majority, but does not find it worthwhile to dissent (Region 3). In such instances, the probability that the full circuit will review is lower compared to when there is a dissent-and the full circuit will only reverse if it discovers that non-compliance actually occurred.

\subsection{Counter-preference signaling predictions}

Having summarized the model, we can now generate theoretical predictions about en banc review and reversal. In the model, the full circuit would only like to expend the cost of review on cases in which non-compliance is particularly severe, because its time is valuable. Imagine, at the extreme, that the whistleblower were to always dissent whenever the panel ruled against the preferences of the circuit. Then the circuit would have no way of discerning the severity of non-compliance across different cases - dissents would not be informative as to severity (though they still would be informative of non-compliance). Conversely, a whistleblower who only dissents from the most severe instances of non-compliance provides a much stronger signal that review is warranted. Thus, dissents signal severe noncompliance most convincingly, and are most effective at triggering review, when they are rare.

Which types of judges are likely to dissent the most, thereby diminishing the impact of their dissents? A whistleblower's incentive to dissent is driven by her desire to see decisions with which she disagrees overturned, because this incentive comes mainly from her preferences over case outcomes. As a result, whistleblowers who are farthest ideologically from the panel majority (i.e. the panel median) will have the most incentive to dissent "too often," and will be least effective at triggering review. On the other hand, whistleblowers who are 

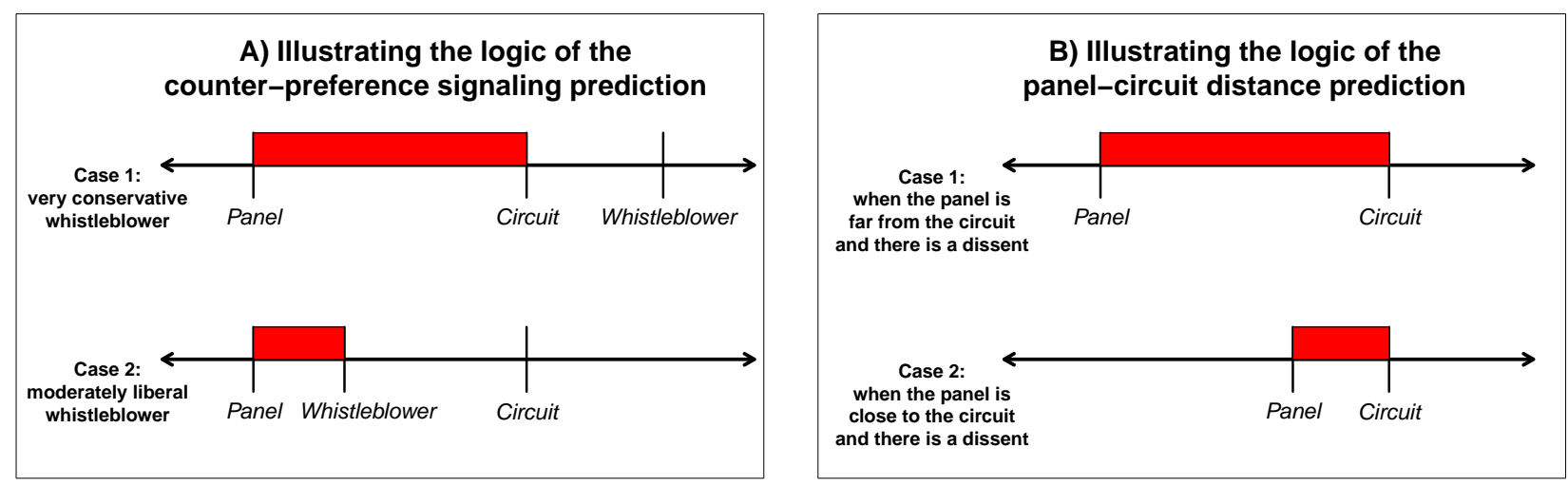

Figure 2: Illustrating the logic of the review predictions. See text for details.

closer to the panel majority (i.e. those who have cutpoints more to the left) who nevertheless choose to dissent will be much more credible messengers of severe non-compliance.

To see the intuition for this effect, suppose that a very conservative judge dissents from a liberal ruling by a liberal panel, as depicted in Case 1 in Figure 2A. While the circuit can be sure that the panel median indeed made a non-compliant decision, the circuit does not know whether the non-compliance was egregious or minor. This is because the conservative whistleblower has an incentive to dissent from a liberal decision whenever the case facts lie anywhere in the shaded interval, which covers the entire conflict region. ${ }^{4}$ Thus, while the circuit can be sure upon observing a dissent that non-compliance occurred, it cannot know whether that non-compliance was egregious or minor.

In contrast, suppose the dissenting judge was instead moderately liberal, as depicted in Case 2 in Figure 2A. Being generally friendly to liberal dispositions, such a judge is only willing to dissent in the smaller shaded region, which contains only the most severe instances of non-compliance. Consequently, the moderate judge's dissent is a much stronger signal of severe non-compliance, and will be more effective at triggering review, compared to a dissent by a very conservative judge. Intuitively, if even a moderately liberal judge dissents from a liberal ruling, a conservative circuit will likely want to review it. We call such dissents "counter-preference signals."

The same intuition generates a less obvious prediction about unanimous cases - a whistle-

\footnotetext{
${ }^{4}$ To be clear, the model does not predict that such a whistleblower will always actually dissent from exactly these cases in equilibrium; just that she has an incentive to signal non-compliance in a wider range of cases.
} 


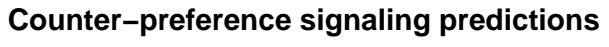

A) Review

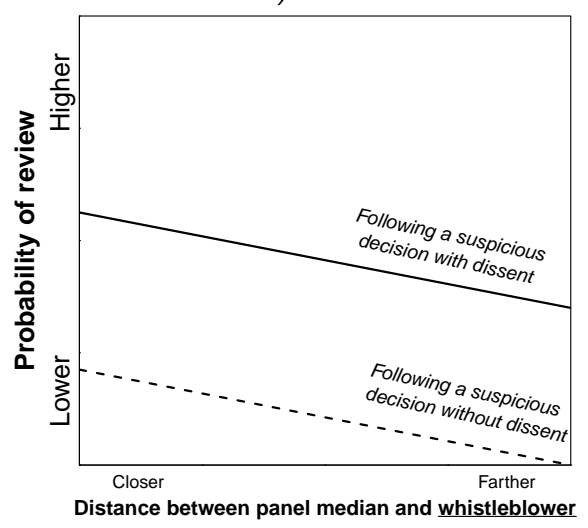

C) Reversal

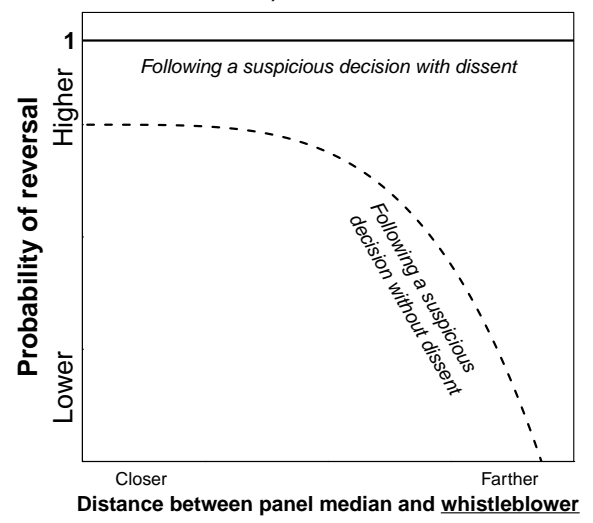

Panel-circuit distance predictions

B) Review

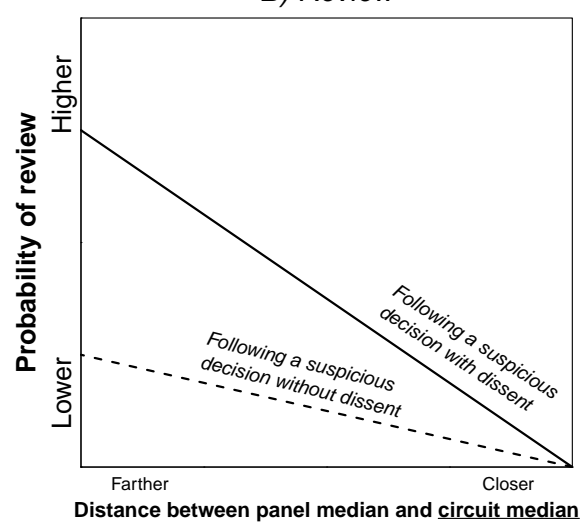

D) Reversal

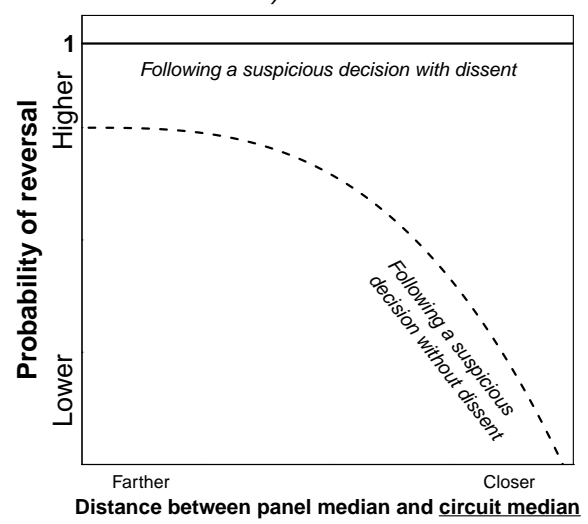

Figure 3: Graphical presentation of the review and reversal hypotheses. See text for details.

blower's silence can be as informative as her dissent. Consider a conservative circuit deciding whether to review a unanimous liberal decision. As the whistleblower moves away from the panel majority and toward the full circuit, the absence of dissent becomes a stronger signal that the circuit would agree with the liberal decision, which decreases the probability of review. Intuitively, if even a conservative judge agrees with a liberal ruling, a conservative circuit will likely not want to review it. As a result, the preferences of whistleblowers affect the likelihood of review, even when no whistle is observed. This leads to:

- The Counter-Preference Signaling Review Hypothesis: The probability of review, both in suspicious decisions with whistleblowing dissents and in unanimous suspicious decisions, decreases as the whistleblower moves farther away from the panel majority.

Figure 3A depicts this argument graphically; it shows the theoretical predicted probabilities of review of cases both with and without dissent as a function of the whistleblower's location (relative to the panel majority). Both functions are highest when the whistleblower is an 
ideological doppelgänger of the panel majority, and then weakly decrease as the whistleblower moves in the direction of the circuit median.

Next consider the full circuit's decision of whether to reverse a decision, conditional on having granted review. Figure 3C depicts the probability of reversal, conditional on review, in cases with and without dissent, as the location of the whistleblower varies. Because the whistleblower only dissents in instances of noncompliance (though possibly very minor ones), if the full circuit reviews a case with a dissent the model predicts that it will always reverse. Conversely, in unanimous cases the full circuit will sometimes discover upon review that the liberal disposition was actually compliant. As the whistleblower moves farther away from the panel, this scenario becomes more likely; thus, the probability of reversing a reviewed unanimous decision decreases. This leads to:

- The Counter-Preference Signaling Reversal Hypothesis: The probability of reversal in unanimous suspicious decisions, conditional on review, decreases as the whistleblower moves farther away from the panel majority.

\subsection{Dissent and the Distance Between the Panel and the Circuit}

While the location of the whistleblower is important for understanding discretionary review and reversal, the ideological distance between the full circuit and the panel majority is also crucial. Indeed, this principal-agent relationship has been the focus of most studies of interactions between higher and lower courts (Cameron, Segal and Songer 2000, Clark 2009, Giles, Walker and Zorn 2006). In our theory, a whistleblowing dissent is most effective in generating review when the panel majority is far from the full circuit (see Case 1 in Figure 2B-we do not depict the whistleblower because the key condition is the presence of a dissent). Under these conditions, the panel majority makes many liberal decisions, and the ones from which the whistleblower dissents are more likely to be severely noncompliant relative to unanimous liberal decisions. Consequently, the circuit is much more likely to review decisions with dissents, and the marginal effect of dissent is large. In contrast, when the panel is near the circuit (see Case 2 in Figure 2B) the disagreement region is small. Most of the panel's decisions are compliant, and when they are not, the degree of non-compliance 
is minor. Consequently, the full circuit is less responsive to dissent. This leads to:

- The Panel-Circuit Distance Review Hypothesis: The marginal effect of whistleblowing dissents in suspicious decisions on the probability of review decreases as the panel majority moves closer to the full circuit.

The effect is illustrated in Figure 3B. The vertical axis again depicts the probability of review, while the horizontal axis depicts the location of the panel median, moving left-toright from farther from the full circuit to closer to it. A similar logic also applies when considering the effect of the location of the panel median (relative to the full circuit) on the probability of reversal in unanimous cases, which leads to:

- The Panel-Circuit Distance Reversal Hypothesis: The probability that the circuit will reverse a unanimous suspicious decision, conditional on review, decreases as the panel majority moves closer to the full circuit.

\subsection{Review and Reversal in Unanimous versus Non-Unanimous Cases}

Finally, the theory makes predictions about the relative likelihood of both review and reversal of suspicious rulings with and without a dissent. Beginning first with the former, for any fixed distance between the panel median and the whistleblower, or between the panel and circuit medians, the probability of review following a dissent is always higher than the probability of review following a unanimous decision. This is because in the theory, dissent always signals more severe non-compliance, while unanimous (suspicious) decisions signal less severe noncompliance or compliance. This leads to:

- The Dissent Versus Unanimity Review Hypothesis: For any given configuration of preferences, the probability of review is always higher in suspicious decisions with whistleblowing dissents than in unanimous suspicious decisions.

As noted above, when the full circuit reviews a case with a whistleblowing dissent, the theory predicts that the probability of reversal is 1 , since whistleblowers only dissent from non-compliant decisions. This prediction is surely too strong, given that both dissents and en banc review occur for reasons outside the model. But, as both Figure 3C and Figure 3D show, the likelihood of reversal is always higher in cases with whistleblowing dissents than in unanimous cases. This leads to: 


\begin{tabular}{|c|c|c|c|}
\hline Name & Hypothesis & $\begin{array}{c}\text { Theoretical } \\
\text { picture }\end{array}$ & $\begin{array}{c}\text { Empirical } \\
\text { picture }\end{array}$ \\
\hline \multicolumn{4}{|c|}{ REVIEW } \\
\hline $\begin{array}{l}\text { The Counter-Preference } \\
\text { Signaling Review } \\
\text { Hypothesis }\end{array}$ & $\begin{array}{l}\text { The probability of review, both in suspicious decisions with } \\
\text { whistleblowing dissents and in unanimous suspicious decisions, } \\
\text { decreases as the whistleblower moves farther away from the panel } \\
\text { majority. }\end{array}$ & Figure $3 \mathrm{~A}$ & Figure $5 \mathrm{~A}$ \\
\hline $\begin{array}{l}\text { The Panel-Circuit } \\
\text { Distance Review } \\
\text { Hypothesis }\end{array}$ & $\begin{array}{l}\text { The marginal effect of whistleblowing dissents in suspicious } \\
\text { decisions on the probability of review decreases as the panel } \\
\text { majority moves closer to the full circuit. }\end{array}$ & Figure 3B & Figure 5B \\
\hline $\begin{array}{l}\text { The Dissent Versus } \\
\text { Unanimity Review } \\
\text { Hypothesis }\end{array}$ & $\begin{array}{l}\text { For any given configuration of preferences, the probability of review } \\
\text { is always higher in suspicious decisions with whistleblowing dissents } \\
\text { than in unanimous suspicious decisions. }\end{array}$ & $\begin{array}{c}\text { Figures } 3 \mathrm{~A} \text { and } \\
3 \mathrm{~B}\end{array}$ & $\begin{array}{c}\text { Figure } 5 \mathrm{~A} \\
\text { and } 5 \mathrm{~B}\end{array}$ \\
\hline \multicolumn{4}{|c|}{$\begin{array}{ll}\text { REVERSAL } \\
\end{array}$} \\
\hline $\begin{array}{l}\text { The Counter-Preference } \\
\text { Signaling Reversal } \\
\text { Hypothesis }\end{array}$ & $\begin{array}{l}\text { The probability of reversal in unanimous suspicious decisions, } \\
\text { conditional on review, decreases as the whistleblower moves farther } \\
\text { away from the panel majority. }\end{array}$ & Figure $3 \mathrm{C}$ & Figure $6 \mathrm{~A}$ \\
\hline $\begin{array}{l}\text { The Panel-Circuit } \\
\text { Distance Reversal } \\
\text { Hypothesis }\end{array}$ & $\begin{array}{l}\text { The probability of reversal in unanimous suspicious decisions, } \\
\text { conditional on review, decreases as the panel majority moves closer } \\
\text { to the higher court. }\end{array}$ & Figure 3D & Figure 6B \\
\hline $\begin{array}{l}\text { The Dissent Versus } \\
\text { Unanimity Reversal } \\
\text { Hypothesis }\end{array}$ & $\begin{array}{l}\text { The probability of reversal, conditional on review, is always higher } \\
\text { in suspicious decisions with whistleblowing dissents than in } \\
\text { unanimous suspicious decisions. }\end{array}$ & $\begin{array}{c}\text { Figures } 3 \mathrm{C} \text { and } \\
3 \mathrm{D}\end{array}$ & $\begin{array}{c}\text { Figure } 6 \\
\text { (entire) }\end{array}$ \\
\hline
\end{tabular}

Table 1: Summary of hypotheses. The last two columns depict where theoretical pictures (above) and empirical pictures (below) of each hypothesis can be found.

- The Dissent Versus Unanimity Reversal Hypothesis: The probability of reversal, conditional on review, is always higher in suspicious decisions with whistleblowing dissents than in unanimous suspicious decisions.

Table 1 collects and summarizes all the hypotheses.

\section{Data and Analysis}

Data To test these predictions, we use both existing and original data on cases heard on the Courts of Appeals. Complete details of our data collection can be found in the Supplemental Appendix; we provide a brief summary here. Testing the theory requires a sample of cases with a sufficient number of en banc reviews to conduct meaningful statistical analysis. We follow the lead of other studies and employ a choice-based approach in which we oversample cases reheard en banc (Giles, Walker and Zorn 2006, Clark 2009, Beim and Kastellec 2014). Specifically, our dataset includes a stratified random sample of Courts of Appeals cases decided between 1986 and 2002 that were not reheard en banc, as well as the universe of three-judge panel decisions in this period that were reheard en banc.

After removing cases with missing observations, our dataset contains 5,589 panel decisions 
(distributed roughly evenly across all 12 circuits), 792 of which were granted en banc review. Note that combining a random sample with a universe of cases requires each observation to be weighted accordingly; the details of the weighting procedures are also described in the Supplemental Appendix. The overall rate of en banc review is about 1\%, meaning only about 1 out of every 100 (published) Courts of Appeals decisions is reviewed en banc.

Of the 792 cases granted review, the full circuit reached their own decision in 772 cases (in the remaining cases, en banc review was terminated before the circuit reached a decision). For these 772 cases, we coded whether the full circuit reversed the panel or not-see the Supplemental Appendix for details on how we coded reversals. Because this set of cases comprises the universe of en banc decisions in this period, we do not need to employ weights for the analysis of reversal decisions. To the best of our knowledge, this dataset comprises the largest number of en banc cases - both in terms of the review decision and the reversal decision - to be subject to a case-level analysis of review. ${ }^{5}$

Dispositions and Preferences To code case dispositions, we rely on the coding protocol in Songer (1999) and code each panel decision as liberal or conservative. If the decision was accompanied by a dissent, we record which judge dissented. For judicial preferences, we rely on the approach of Giles, Hettinger and Peppers (2001). The GHP scores, higher values of which indicate that a judge is more conservative, are based on the Common Space score of a judge's appointing president and/or home state senators.

Testing the theory requires estimates of the preferences of the full circuit, the panel, and the whistleblower. We define the full circuit's indifference point by using the GHP score of the median active judge on the circuit at the time a case was heard (we call this variable "circuit median"). Similarly, we define the panel majority as the panel median: the median GHP score of the three judges on the panel. To measure the preferences of the whistleblower, we use the following procedure. If the panel median is more liberal than the circuit median, define the whistleblower as the most conservative judge on the panel. If the panel median is

\footnotetext{
${ }^{5}$ Giles et al. (2007) evaluate the universe of en bancs from 1942 to 1999 from a macro perspective, using the number of en bancs in a given circuit-year as their dependent variable.
} 
more conservative than the circuit median, define the whistleblower as the most liberal judge on the panel. The whistleblower is thus the panel judge most ideologically biased against the disposition favored by the panel majority, relative to the full circuit. Importantly, this operationalization depends on the exogenous preferences of the relevant actors and their relative configuration, rather than the endogenous votes that they cast. ${ }^{6}$ So, as in the theory, the judge we identify as the whistleblower may or may not actually dissent.

With these measures in hand, we can define the relevant distance measures in the theory. First, Panel-circuit distance is the absolute value of the distance between the panel median and the circuit median. Second, given our operationalization of the preferences of the whistleblower, panel-whistleblower distance is simply the absolute value of the distance between the panel and the whistleblower. ${ }^{7}$

Suspicious decisions and whistleblower dissents Next, the theory makes predictions about the circuit's review and reversal behavior as a function of whether the panel made a suspicious decision, and whether the whistleblower dissented. ${ }^{8}$ We define a suspicious decision as one in which the full circuit cannot be sure if the panel's decision is compliant. Specifically, define a decision as suspicious if either a panel that is more liberal than the circuit makes a liberal decision, or a panel that is more conservative than the circuit makes a conservative decision. ${ }^{9}$ Next, we define a whistleblower dissent as a dissent by the judge

\footnotetext{
${ }^{6}$ In the Supplemental Appendix we show that our results are robust to using an alternative operationalization of the whistleblower based on the votes on the panel.

${ }^{7}$ Note that the whistleblower is always on the same side of the panel median as the circuit median, but can be on either side of the circuit median.

${ }^{8}$ Other studies have noted that the relative position of the Supreme Court may condition the likelihood of review; for example, a liberal circuit that is distant from a conservative Supreme Court may be less inclined to review a conservative panel decision, compared to a conservative circuit deciding whether to review a liberal panel decision (Clark 2009, Beim and Kastellec 2014). As was the case with these studies, a vast majority of the cases in our data (around 80\%) were decided in Republican-controlled circuits (i.e. conservative circuits), making it difficult to get leverage on this question. (Clark (2009), for example, does not find a statistically significant difference in the likelihood of review based on the position of the Supreme Court, likely because an even greater proportion of cases in the dataset he used were decided in Republican-controlled circuits.)

${ }^{9}$ This is analogous to what Giles, Walker and Zorn (2006) call a "minority" decision (minority with respect to the circuit) and the converse of what Clark (2009) calls an "opposite" decision (opposite with respect to the panel's relative preferences).
} 
A)

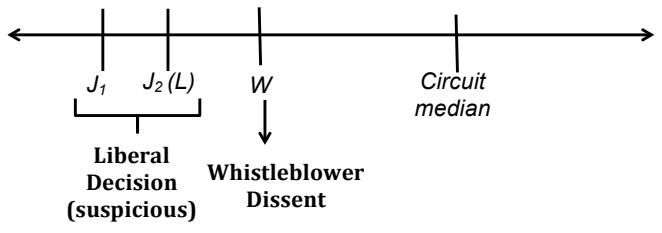

C)

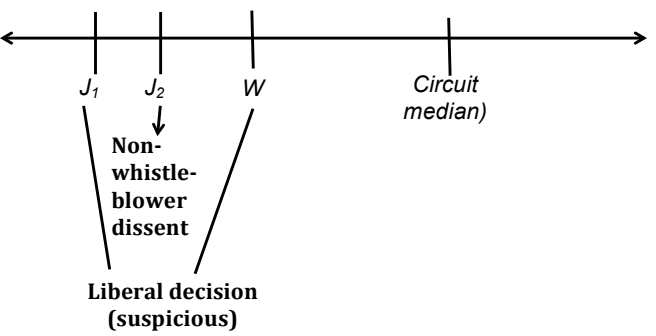

B)
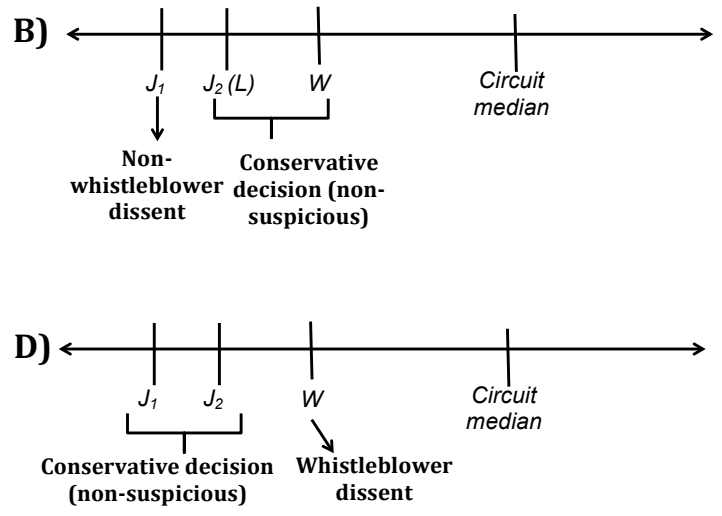

Figure 4: Illustrations of dissents both consistent and inconsistent with the theory. See text for details.

who we have defined as the whistleblower. ${ }^{10}$

Behavior outside the theory The theory solely models what we have called whistleblowing dissents - dissents by a whistleblower that are intended to signal noncompliance and trigger review and reversal. Accordingly, such dissents occur only from suspicious decisions. This scenario is depicted in Figure 4A. Let $W$ denote the judge we identify as the whistleblower, and $J_{1}$ and $J_{2}$ the remaining two judges on the panel, with $J_{2}$ being the median of the panel. In the example all three judges are more liberal than the circuit. ${ }^{11}$ In Figure $4 \mathrm{~A}$, the two most-liberal judges vote liberally, thereby creating a suspicious decision, from which $W$ dissents.

In reality, however, judges dissent for many reasons, and connecting theory to data requires accounting for such behavior that is outside the theory yet present in the data. This includes dissents from non-suspicious decisions, which never occur in the theory (since a non-suspicious decision is a perfect signal of compliance). For example, in Figure 4B, the judge we identify as the whistleblower joins the median in deciding the case conservatively, thereby creating a non-suspicious decision. The most liberal judge casts a liberal dissent,

\footnotetext{
${ }^{10}$ In some cases, two judges will share the same GHP score, and thus they will be jointly identified as the whistleblower. If either of these judges dissented, then we classify that dissent as a "whistleblower dissent." (These are the cases where the panel median's ideological doppelgänger dissented).

${ }^{11}$ Recall that in our empirical analyses we consider any possible configuration, including ones where the circuit is more liberal than the panel median, and where the whistleblower is on the opposite side of the circuit from the panel median.
} 
perhaps to assert her sincere opposition. In Figure 4C, the most liberal and most conservative judges on the panel join to cast a suspicious liberal decision. The panel median dissents, perhaps on technical grounds, even though based on ideology alone she should prefer a liberal decision whenever her more conservative colleague does. ${ }^{12}$ Finally, in Figure $4 \mathrm{D}$ the whistleblower dissents from a non-suspicious decision; in theory, she should both agree with such a disposition, and expect that her dissent will not trigger a review anyway. We employ flexible model specifications that allow us to distinguish among these different scenarios. In doing so, we can validate our empirical results by demonstrating that the effects of preferences are only present in circumstances where the theory predicts that such effects should occur.

\subsection{Evaluating en banc review}

We begin by testing the review predictions, and then turn to evaluating the reversal predictions. The first three models in Table 2 present weighted logit models of en banc review, where the dependent variable is coded 1 if a circuit voted to rehear a case en banc, and 0 otherwise. (Models 4-6 are models of reversal-we return to them below). Each model contains our core specification, as follows. The theory predicts that (i) the preferences and behavior of the whistleblower will influence the probability of review, but only on suspicious decisions, and (ii) these effects will be conditioned by the distance between the panel median and the circuit median. Accordingly, for our main empirical test we include the following predictors: whistleblower dissent, suspicious decision, panel-whistleblower distance, and panel-circuit distance. To test our hypotheses we include the three-way interactions between: a) whistleblower dissent, suspicious decisions, and panel-whistleblower distance; and b) whistleblower dissent, suspicious decisions, and panel-circuit distance. We also include all the two-way interactions among the respective three-way interactions as their own

\footnotetext{
${ }^{12}$ Such a scenario may also occur in the data due to measurement error. In particular, the GHP scores may not sufficiently discriminate among judges of the same party; that is, the scores may classify one Republican judge on a panel as slightly more conservative than another Republican on a panel when the opposite is true. An alternative approach would be to count dissents as whistleblower dissents if the actual dissenter is "close enough" to the projected whistleblower. Our approach is thus conservative, as we are likely classifying many dissents that actually fall under the category of whistleblowing as non-whistleblowing.
} 


\begin{tabular}{|c|c|c|c|c|c|c|}
\hline & \multicolumn{3}{|c|}{ Review Models } & \multicolumn{3}{|c|}{ Reversal Models } \\
\hline & (1) & $(2)$ & (3) & (4) & $(5)$ & (6) \\
\hline Intercept & $\begin{array}{r}-5.57 \\
(0.16)\end{array}$ & $\begin{array}{c}-6.44 \\
(0.19)\end{array}$ & $\begin{array}{c}-6.23 \\
(0.40)\end{array}$ & $\begin{array}{c}0.11 \\
(0.28)\end{array}$ & $\begin{array}{c}-0.16 \\
(0.30)\end{array}$ & $\begin{array}{r}-1.43 \\
(0.65)\end{array}$ \\
\hline Whistleblower dissent & $\begin{array}{c}1.80 \\
(0.51)\end{array}$ & $\begin{array}{c}2.27 \\
(0.52)\end{array}$ & $\begin{array}{c}2.33 \\
(0.55)\end{array}$ & $\begin{array}{c}1.12 \\
(0.72)\end{array}$ & $\begin{array}{c}1.22 \\
(0.73)\end{array}$ & $\begin{array}{c}1.57 \\
(0.77)\end{array}$ \\
\hline Susp. decisions & $\begin{array}{c}0.27 \\
(0.20)\end{array}$ & $\begin{array}{c}0.38 \\
(0.22)\end{array}$ & $\begin{array}{c}0.49 \\
(0.24)\end{array}$ & $\begin{array}{c}0.36 \\
(0.37)\end{array}$ & $\begin{array}{c}0.35 \\
(0.37)\end{array}$ & $\begin{array}{c}0.29 \\
(0.40)\end{array}$ \\
\hline Panel-whistleblower $(P-W)$ distance & $\begin{array}{c}1.15 \\
(0.30)\end{array}$ & $\begin{array}{c}0.74 \\
(0.35)\end{array}$ & $\begin{array}{c}0.61 \\
(0.38)\end{array}$ & $\begin{array}{c}1.18 \\
(0.52)\end{array}$ & $\begin{array}{c}1.06 \\
(0.53)\end{array}$ & $\begin{array}{c}1.14 \\
(0.57)\end{array}$ \\
\hline Panel-circuit $(P-C)$ distance & $\begin{array}{c}-0.77 \\
(0.43)\end{array}$ & $\begin{array}{c}-0.19 \\
(0.47)\end{array}$ & $\begin{array}{c}-0.47 \\
(0.48)\end{array}$ & $\begin{array}{c}-1.71 \\
(0.66)\end{array}$ & $\begin{array}{c}-1.58 \\
(0.67)\end{array}$ & $\begin{array}{r}-2.09 \\
(0.72)\end{array}$ \\
\hline Susp. decision $\times(P-W)$ distance & $\begin{array}{c}-2.04 \\
(0.37)\end{array}$ & $\begin{array}{c}-1.47 \\
(0.44)\end{array}$ & $\begin{array}{c}-1.49 \\
(0.47)\end{array}$ & $\begin{array}{c}-1.44 \\
(0.68)\end{array}$ & $\begin{array}{c}-1.26 \\
(0.69)\end{array}$ & $\begin{array}{c}-1.22 \\
(0.74)\end{array}$ \\
\hline Susp. decision $\times(P-C)$ distance & $\begin{array}{c}3.54 \\
(0.51)\end{array}$ & $\begin{array}{c}2.98 \\
(0.56)\end{array}$ & $\begin{array}{c}2.96 \\
(0.58)\end{array}$ & $\begin{array}{c}2.83 \\
(0.85)\end{array}$ & $\begin{array}{c}2.71 \\
(0.86)\end{array}$ & $\begin{array}{c}3.11 \\
(0.92)\end{array}$ \\
\hline Whistleblower dissent $\times$ Susp. decision & $\begin{array}{c}1.03 \\
(0.61)\end{array}$ & $\begin{array}{c}0.88 \\
(0.61)\end{array}$ & $\begin{array}{c}1.06 \\
(0.65)\end{array}$ & $\begin{array}{c}-0.31 \\
(0.88)\end{array}$ & $\begin{array}{c}-0.29 \\
(0.88)\end{array}$ & $\begin{array}{r}-0.54 \\
(0.93)\end{array}$ \\
\hline Whistleblower dissent $\times(P-W)$ distance & $\begin{array}{r}-0.38 \\
(0.77)\end{array}$ & $\begin{array}{r}-0.10 \\
(0.83)\end{array}$ & $\begin{array}{r}-0.03 \\
(0.85)\end{array}$ & $\begin{array}{c}-2.22 \\
(1.76)\end{array}$ & $\begin{array}{c}-2.04 \\
(1.77)\end{array}$ & $\begin{array}{r}-1.73 \\
(1.92)\end{array}$ \\
\hline Whistleblower dissent $\times(P-C)$ distance & $\begin{array}{c}1.48 \\
(0.97)\end{array}$ & $\begin{array}{c}1.14 \\
(0.98)\end{array}$ & $\begin{array}{c}1.44 \\
(1.01)\end{array}$ & $\begin{array}{c}0.55 \\
(2.14)\end{array}$ & $\begin{array}{c}0.42 \\
(2.13)\end{array}$ & $\begin{array}{r}-0.47 \\
(2.23)\end{array}$ \\
\hline Whistleblower dissent $\times$ Susp. decision $\times P-W$ distance & $\begin{array}{c}-0.83 \\
(1.01)\end{array}$ & $\begin{array}{c}-1.16 \\
(1.06)\end{array}$ & $\begin{array}{c}-1.62 \\
(1.07)\end{array}$ & $\begin{array}{c}1.19 \\
(1.99)\end{array}$ & $\begin{array}{c}1.00 \\
(2.00)\end{array}$ & $\begin{array}{c}0.53 \\
(2.14)\end{array}$ \\
\hline Whistleblower dissent $\times$ Susp . decision $\times P$-C distance & $\begin{array}{l}-0.95 \\
(1.17)\end{array}$ & $\begin{array}{l}-0.71 \\
(1.19)\end{array}$ & $\begin{array}{l}-0.75 \\
(1.21)\end{array}$ & $\begin{array}{c}0.91 \\
(2.39)\end{array}$ & $\begin{array}{c}0.96 \\
(2.38)\end{array}$ & $\begin{array}{c}1.61 \\
(2.51)\end{array}$ \\
\hline Non-whistleblower dissent & & $\begin{array}{c}2.47 \\
(0.13)\end{array}$ & $\begin{array}{c}2.53 \\
(0.14)\end{array}$ & & $\begin{array}{c}0.35 \\
(0.19)\end{array}$ & $\begin{array}{c}0.26 \\
(0.21)\end{array}$ \\
\hline Panel reversed lower court & & $\begin{array}{c}0.74 \\
(0.11)\end{array}$ & $\begin{array}{c}0.78 \\
(0.11)\end{array}$ & & $\begin{array}{c}0.25 \\
(0.16)\end{array}$ & $\begin{array}{c}0.30 \\
(0.18)\end{array}$ \\
\hline$N$ & 5589 & 5589 & 5589 & 772 & 772 & 772 \\
\hline $\mathrm{AIC}$ & 127.10 & 129.95 & 190.72 & 934 & 932 & 947 \\
\hline
\end{tabular}

Table 2: Regression models. Models 1-3 present models of en banc review. Each of these models is a weighted logit. Models 4-6 are models of whether the full circuit reverses the panel, among those cases granted review. These models are regular logits. Standard errors in parentheses. Fixed effect for circuits, years, and issues are estimated in Models 3 and 6, but not displayed.

constituent terms in the model. ${ }^{13}$ Model 1 includes only these predictors.

As noted above, dissent and en banc review also occur for reasons outside the theory. Thus, in Model 2 we include several additional predictors. First, we define an additional variable non-whistleblower dissent as a dissent by a judge who we did not identify as the whistleblower. We allow this variable to enter the model as a main effect; to the extent that dissents by judges other than the whistleblower may boost the likelihood of review, this variable accounts for that. Next, whether the three-judge panel reversed the district court decision (or agency decision) has also been shown to be a strong predictor of en banc

\footnotetext{
${ }^{13}$ An alternative strategy would be to allow the interaction of whistleblower dissent $\times$ suspicious decision to enter the models as a single variable, coded 1 if the whistleblower dissented in a suspicious case, and 0 otherwise. Because interactive models are difficult to interpret when all main effects are not included, we choose to enter all the main effects separately and then analyze the relevant interactions.
} 
review (George 1999); to account for this we include the variable panel reversed lower court. Finally, as a robustness check, Model 3 adds fixed effects for circuits and years to account for any heterogeneity across time or space, or both. We also include fixed effects for issue areas - following Clark (2009), we classify each case into one of four categories: civil rights, criminal procedure, economic issues, and miscellaneous.

Due to the number of interaction terms in a non-linear model, the coefficients on the key predictors are not readily interpretable. We thus move to examining substantive quantities of interest to test the theoretical predictions. Looking across models, we see that the coefficients and standard errors are very similar. The AIC measures, which assess model fit while accounting for the number of covariates, suggest that Models (1) and (2) are superior to (3). We use the results from Model (2) going forward. To present the results of the model, we calculate "average predicted probabilities" using the observed values in our data (Gelman and Pardoe 2007, Hanmer and Kalkan 2013). In addition, we use simulations of the coefficients from the model (based on variances and covariances) to compute $95 \%$ confidence intervals on all of our quantities of interest. ${ }^{14}$

\subsubsection{Counter-preference signaling results}

We begin our analysis of review decisions by evaluating the counter-preference signaling predictions, which are that the probability of review of suspicious decisions, in both cases with whistleblower dissents and in unanimous cases, decreases as the whistleblower moves farther away from the panel median. Figure 5A presents the test of the Counter-Preference Signaling Review Hypothesis. The vertical axis depicts the probability of review, while the horizontal axis depicts the distance between the panel median and the whistleblower. (One can think about this by assuming the panel is less conservative than the circuit: the whistleblower "slides" away from the panel and toward the circuit as it moves to the right.) The shaded region around the line shows the $95 \%$ confidence interval.

\footnotetext{
${ }^{14}$ Our inferential approach is in the spirit of King, Tomz and Wittenberg (2000). After running our regression models, we run simulations to get estimates of the distribution of the relevant coefficients. We then use these simulations to both generate substantive quantities of interest and make probabilistic statements about the strength of the theoretical predictions.
} 

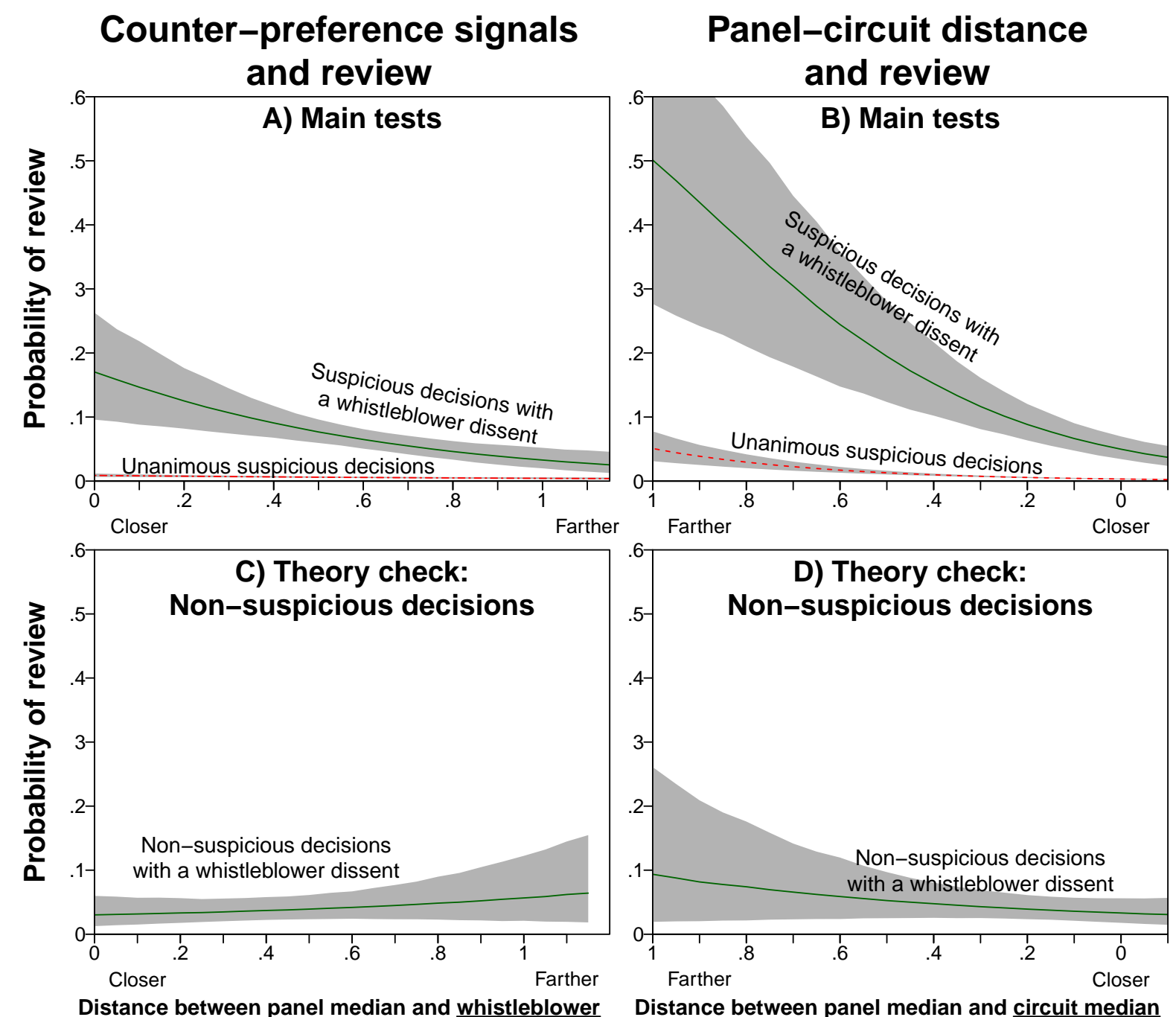

Figure 5: Predicted probabilities of en banc review. A) How the probability of review changes as the distance between the panel median and whistleblower increases, in suspicious decisions with whistleblower dissents and in unanimous suspicious decisions B) How the probability of review changes as the distance between the panel median and circuit median decreases, in suspicious decisions with whistleblower dissents and in unanimous suspicious decisions. C) How the probability of review changes as the distance between the panel median and whistleblower increases, in non-suspicious decisions with whistleblower dissents. D) How the probability of review changes as the distance between the panel median and circuit median decreases, in non-suspicious decisions with whistleblower dissents.

Beginning with suspicious decisions with whistleblower dissents (the solid line in Figure 5A), the results clearly support the Counter-Preference Signaling Review Hypothesis. The largest probability of review occurs when the whistleblower is closest to the panel median, and declines as the whistleblower moves farther away. The effect is substantively large. The predicted probability of review when the ideology of the whistleblower equals that of the panel majority is .17 (95\% confidence interval of $[.10, .26])$, a strikingly high rate given the 
rarity of en banc review (recall the overall rate of en banc in our data is about .01). When the whistleblower is most distant from the panel majority, the predicted probability of review declines to $.03[.01, .05]$.

How does the location of the whistleblower affect review in unanimous decisions? The dashed line depicts the probability of review in suspicious decisions from which neither the whistleblower nor any other judge dissents. Consistent with the Counter-Preference Signaling Review Hypothesis applied to unanimous cases, the rate of review does decline at a statistically significant rate as the whistleblower moves away from the panel median. ${ }^{15}$ However, Figure 5A reveals that the effect is not substantively meaningful, for the simple fact that the average predicted rate of review for cases without dissent is always very small. ${ }^{16}$ Even when the whistleblower has the same ideology as the panel median (meaning the entire panel is equally distant from the circuit) the probability of review is about .009 [.007, .012].

\subsubsection{Panel-circuit distance results}

We now turn to analyzing the Panel-Circuit Distance Review Hypothesis, which predicts that whistleblower dissents are more likely to trigger review when the panel majority is further from the full circuit. Figure $5 \mathrm{~B}$ presents the results of this test. The vertical axis again depicts the probability of review, while the horizontal axis depicts the distance between the panel and circuit medians, moving closer from left to right.

The results support the Panel-Circuit Distance Review Hypothesis. Recall that this hypothesis is a prediction about changes in the marginal effect of dissent on the probability of review as the panel majority moves closer to the full circuit. When the panel is the maximum distance away from the full circuit, a unanimous suspicious decision has about a .05 [.03,.08] chance of being reviewed. This shows that full circuits do review suspicious unanimous decisions by very distant panels at a substantial rate (compared to the baseline

\footnotetext{
${ }^{15}$ In actuality, of course, the whistleblower has not "blown the whistle" in unanimous cases. For ease of presentation, throughout the discussion of the results we refer to the potential whistleblower as "the whistleblower" even in unanimous cases.

${ }^{16}$ As we show below, when the panel majority is far from the full circuit, unanimous suspicious decisions are reviewed at a substantively meaningful rate. What 5A shows is that for the average panel in which all three members share similar ideologies, the chance of review given a unanimous decision is very small.
} 
probability of en banc review). For the same panel, however, a whistleblower dissent increases that probability of review of a suspicious decision all the way to .51 [.28,.71], a huge increase of 46 percentage points. Even when the panel is only .4 units (the 75th percentile) away from the full circuit, the differences are dramatic. For such panels, the probability of review increases from $.007[.006, .009]$ in a unanimous suspicious decision to $.11[.08, .16]$ with a whistleblower dissent. Finally, when the panel median approaches the same ideology as the circuit median, the probability of review is effectively zero (.003) in a unanimous case; it increases to $.04[.02, .06]$ in the presence of a whistleblower dissent. Thus, a whistleblower dissent is most likely to trigger review when the panel median is distant from the circuit, and the marginal effect of dissent is also largest when this occurs, as our theory predicts.

\subsubsection{Evaluating dissent versus unanimity}

Finally, we evaluate the Dissent Versus Unanimity Review Hypothesis, which predicts that suspicious decisions with whistleblower dissents are more likely to be reviewed than unanimous suspicious decisions. Consistent with the hypothesis, Figure 5A and Figure 5B respectively show that for any given distance between the panel median and the whistleblower or the panel and circuit medians, the probability of review of a suspicious decision with a whistleblower dissent is always higher than the probability of review of a unanimous suspicious decision. Thus, we see that whether there is a dissent - as well as who dissents - is a key driver of en banc review.

\subsubsection{Theory check: evaluating non-suspicious decisions}

According to our theory, non-suspicious decisions should not be reviewed en banc, nor should whistleblowers dissent from them. However, such reviews and dissents do occur, for reasons outside the theory. This allows us to validate our claims that the dynamics examined by our theoretical model are driving the results in Figure 5A and Figure 5B. We do so by demonstrating that these effects of ideology do not hold for non-suspicious decisions.

First, Figure 5C illustrates the effect of the distance between the whistleblower and the panel median on the probability that a non-suspicious decision with a whistleblower 
dissent will be reviewed. It shows that there is no relationship between this distance and the likelihood of review. The confidence intervals around the line do not include zero, indicating that whistleblower dissents in non-suspicious decisions do increase the overall the probability of review. But, as our theory predicts, this increase in the probability of review does not vary in the location of the whistleblower. Intuitively, this means the following. Consider a panel composed of two liberal judges and one conservative whistleblower, deciding a case in a conservative circuit. If the conservative judge dissents from a conservative decision, this increases the probability of review — cases with any type of dissent are more likely to be reviewed than unanimous decisions. But, unlike the effect in suspicious decisions seen in 5A, the effect is the same regardless of how conservative the whistleblower is.

The same is true for the effect of panel-circuit distance in non-suspicious decisions. Figure 5D presents a parallel result to that presented in Figure 5B. It depicts the probability that a non-suspicious decision with a whistleblower dissent will be reviewed, as a function of the distance between the panel and the circuit median. Again, such dissents significantly increase the chance of a case being reheard en banc. Here the slope of the line is negative and marginally significant (there is a $90 \%$ probability the leftmost point on the line is higher than the rightmost). But the increase in probability is only meaningful in panels that are very distant from the full circuit. In addition, the magnitude of the effect of a whistleblower dissent on review is substantially smaller than the corresponding magnitudes in whistleblower dissents from suspicious decisions. Finally, while we do not depict this in the interest of clarity, the probability of reviewing a non-suspicious unanimous decision is always less than $1 \%$, as we would expect.

\subsection{Reversals}

Next we analyze the full circuit's decision whether to reverse or uphold the panel's decision in the cases that are reheard en banc. In our data, the full circuits reversed $68 \%$ of the decisions they reheard en banc. Models 4-6 in Table 2 present models of reversal that parallel Models 1-3 in terms of the predictors included in each model. We use Model 5 to generate 
predicted probabilities, which are plotted in Figure 6. We focus solely on the probability of reversal in suspicious decisions, because the theory predicts that non-suspicious decisions should not be reviewed, and thus makes no predictions about how the full circuit should treat such cases, should they be reviewed. ${ }^{17}$ We test three reversal hypotheses: the first about the effect of the whistleblower's distance from the panel majority, the second about the effect of the distance between the panel and the full circuit, and the third about the effect of whistleblower dissents as compared to unanimity. Because the probabilities of reversal in cases with and without dissent are more similar than the comparable probabilities of review, we plot the estimates of reversal without uncertainty in Figure $6 \mathrm{~A}$ and $6 \mathrm{~B}$ - for both the Counter-Preference Signaling and Panel-Circuit Distance predictions. We then plot the difference between the two estimates, along with the $95 \%$ confidence intervals around that difference.

We begin by evaluating the Counter-Preference Signaling Reversal Hypothesis and the Panel-Circuit Distance Reversal Hypothesis. These predict that the probability of reversal should decline in unanimous suspicious cases both as the whistleblower moves farther away from the panel median and as the panel median moves closer to the full circuit, respectively. The dashed lines in Figures $6 \mathrm{~A}$ and $6 \mathrm{~B}$ depict the probability of reversal in unanimous suspicious decisions. As predicted, the probability of reversal is decreasing in both distances. However, the negative slope is statistically significant only with respect to the distance between the panel and circuit medians (there is only a $70 \%$ probability that the slope of the line for panel-whistleblower distance is negative). Thus, the data do not support the Counter-Preference Signaling Reversal Hypothesis. However, with respect to the PanelCircuit Distance Reversal Hypothesis, the magnitude of the effect of panel-circuit distance is sizable. When the full circuit reviews a unanimous decision by a maximally distant panel, the probability of reversal is $.82[.65, .92]$. This declines to $.56[.46, .67]$ when the panel

\footnotetext{
${ }^{17}$ In fact, two-thirds of the cases reviewed en banc in our data were of suspicious decisions. An alternative empirical strategy would be to include only suspicious decisions in the regressions in Models 4-6 in Table 2. The results we present in Figure 6 are substantively and statistically the same if we do this.
} 
Counter-preference signals

and reversal
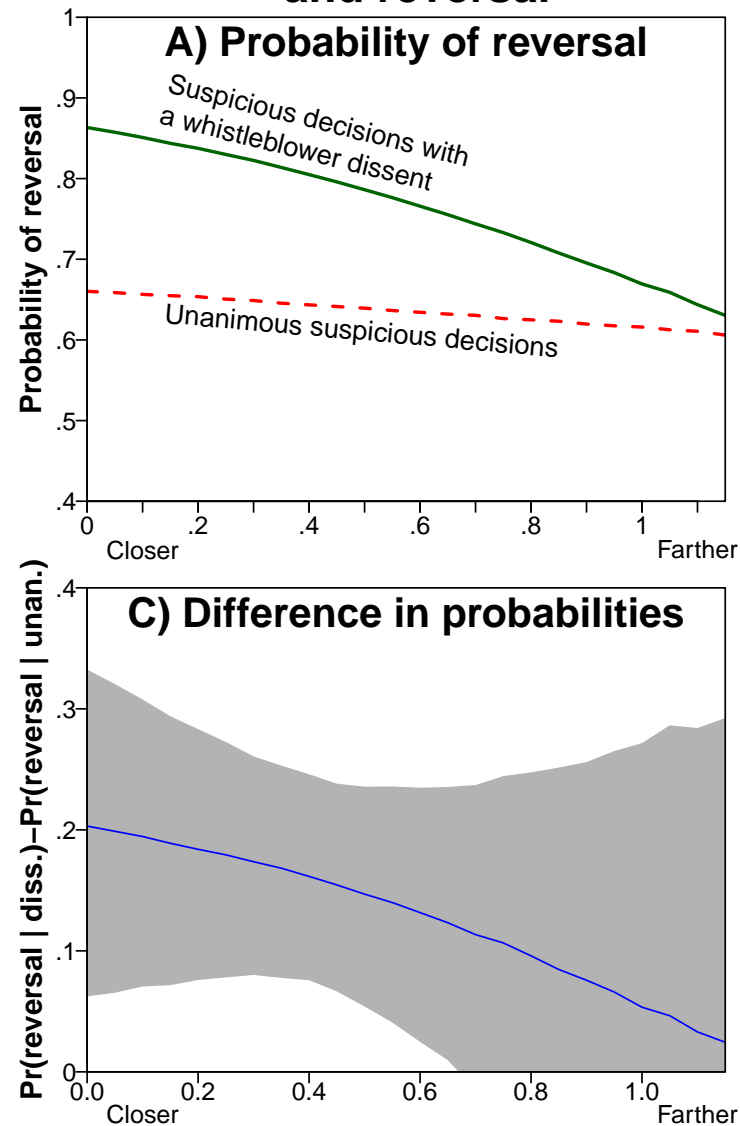

Distance between panel median and whistleblower
Panel-circuit distance and reversal
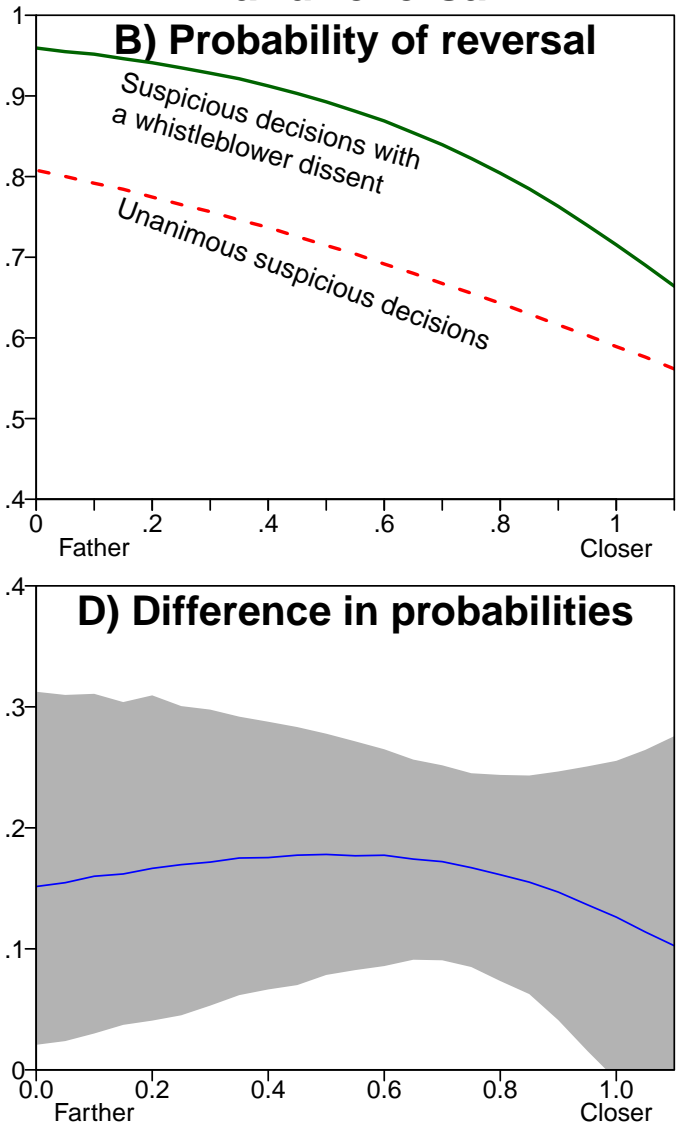

Distance between panel median and circuit median

Figure 6: Predicted probabilities of en banc reversal. A) How the probability of reversal changes as the distance between the panel median and whistleblower increases, in suspicious decisions with whistleblower dissents and in unanimous suspicious decisions. B) How the probability of reversal changes as the distance between the panel median and circuit median decreases, in suspicious decisions with whistleblower dissents and in unanimous suspicious decisions. C) The difference in the probability of reversal in suspicious decisions with a whistleblower dissent versus unanimous suspicious decisions, as the distance between the panel median and whistleblower increases, along with $95 \%$ confidence intervals (i.e. the difference between the two lines in (A)). D) The difference in the probability of reversal in suspicious decisions with whistleblower dissents versus unanimous suspicious decisions, as the distance between the panel median and circuit median decreases, along with 95\% confidence intervals (i.e. the difference between the two lines in (B)).

median has the same ideology as the full circuit - this is well below the average probability of reversal across all cases.

Turning to the probability of reversal in suspicious decisions with a whistleblower dissent, it is easy to see from the solid lines in Figure 6A and Figure 6B that such decisions are not always reversed, contrary to the theory's strong prediction. As noted above, the fact that 
this prediction fails is not surprising, given that both dissents and en banc review occur for reviews outside the model. In fact, the probability of reversal declines across both panelwhistleblower distance and panel-circuit distance in suspicious decisions with whistleblower dissents. (Both of the negative slopes are statistically significant). While this is outside the scope of the model, it is notable that the highest likelihood of reversal occurs when a whistleblower most credibly signals severe non-compliance-when she is close to the panel median, and when the panel median and full circuit are far apart.

Finally, consistent with the Dissent Versus Unanimity Reversal Hypothesis, Figure 6 reveals that the probability of reversal is always higher in cases with whistleblower dissents than in unanimous cases. Figure $6 \mathrm{C}$ and Figure $6 \mathrm{D}$ show that this difference in probabilities is significant across the majority of the range of panel-whistleblower distance and virtually all of the range of panel-circuit distance. Thus, conditional on review, suspicious decisions with whistleblower dissents are more likely to both be reviewed and reversed than unanimous suspicious decisions.

\section{Discussion and Conclusion}

Oversight is inherently difficult in large hierarchies, and the judiciary is no exception. Most cases that reach the federal courts end at the district courts. Of those appealed to the circuit courts, only a fraction are reheard either en banc or by the Supreme Court. On its face, this would suggest an insurmountable principal-agent problem. Yet our paper shows that this pessimism is unwarranted-full circuits can successfully delegate decision making to three-judge panels. While our paper does not provide a comprehensive account of every aspect of en banc review, our results do suggest that the combination of wellknown preferences and informative signaling aid full circuits in selecting cases in which the panel's decision is truly worth reviewing. And while judges are not "whistleblowers" in the traditional sense, dissents operate as meaningful "whistles" with which judges can signal potential non-compliance to their colleagues in the full circuit.

While the importance of dissent within studies of the judicial hierarchy has long been 
understood, we show here that not all dissents are equal-some whistleblowers are more influential than others. Based on a formal theory in Beim, Hirsch and Kastellec (2014), we identify nuanced, novel predictions that describe which dissents will be most likely to lead to discretionary review. We show that a whistleblowing dissent is most effective when the panel majority is furthest from the full circuit - an intuitive prediction. We then show a more nuanced and surprising result. The effect of a whistleblower's dissent on the likelihood of review is strongest when she is ideologically closest to the panel, while the effect of her silence is strongest when she is ideologically most distant from the panel. We show, further, that these effects exist only when a panel makes a decision of which the full circuit is suspicious $e x$ ante. Thus, we find that strategic communication is conditional on the relationship between the receiver and the sender and on the material being communicated. While other work has found such asymmetries with respect to full circuits and panels, our work is the first to show that the power of dissent is also conditional in this manner, and is the first to empirically identify which whistleblowers' dissents are most likely to be heeded.

More broadly, our results help clarify how important dissent is as a communication device in the judicial hierarchy. As we noted earlier, a wealth of previous studies have shown a strong and systematic relationship between dissent and discretionary review. However, one explanation for this finding is that dissent is simply correlated with other factors that also increase the probability of discretionary review, and thus the causal effect of dissent might not be as large as suggested by this literature - or even exist at all. (A similar debate has arisen over whether amicus curiae briefs really have a causal effect on the Supreme Court's case selection; see Caldeira, Wright and Zorn (2012)). However, our finding that the impact of dissent is mediated by the preferences of judicial whistleblowers suggests that at least some of this relationship is due to the signal of dissent itself. The reason is that, given random assignment on the Courts of Appeals, the assignment of a judge with a particular preference to a panel is effectively random (conditional on circuit). Thus, the fact that different dissenters create different probabilities of review, and not simply the act of dissent, 
makes it unlikely that other unobserved characteristics of cases are driving our results.

In addition, our study goes beyond most existing work by connecting the review and reversal decisions with an integrated formal and empirical model. We show that the same decisions that are most likely to be reviewed are also those most likely to be reversed, particularly suspicious decisions with dissenting opinions. This result is consistent with higher courts relying on informative dissents to relay non-compliance by three-judge panels.

At the same time, our study focuses on a particular role for dissent, and thus there remain many open questions about its importance - both at the en banc stage and across appellate courts more broadly. We argued earlier that en banc review is mainly a mechanism for error correction, and our results suggest this is correct. Yet, it is well-known that law creation is another important component of full circuit review. What is the role of dissent when the law is unformed or unclear? This question is even more pertinent with respect to the Supreme Court, given the priority the justices place on law creation over error correction when weighing which cases to review. How do signaling and counter-preference signaling inform appellate court decision making when judges are creating and modifying the law? Finally, how does judicial reputation and prestige affect the ability of a judge to communicate via dissent either up or down the hierarchy (Bhattacharya and Smyth 2001, Klein and Morrisroe 1999)? Theoretical and empirical work on these fronts would further increase our understanding of the importance of dissent in the judicial hierarchy.

\section{References}

Austen-Smith, David and Timothy J Feddersen. 2008. "Public Disclosure, Private Revelation or Silence: Whistleblowing Incentives and Managerial Policy." Northwestern University Working Paper.

Banks, Christopher P. 1999. Judicial Politics in the DC Circuit Court. JHU Press.

Beim, Deborah, Alexander V. Hirsch and Jonathan P. Kastellec. 2014. "Whistleblowing and Compliance in the Judicial Hierarchy." American Journal of Political Science 58(4):904918.

Beim, Deborah and Jonathan P. Kastellec. 2014. "The Interplay of Ideological Diversity, Dis- 
sents, and Discretionary Review in the Judicial Hierarchy: Evidence from Death Penalty Cases." Journal of Politics 76(4):1074-88.

Bhattacharya, Mita and Russell Smyth. 2001. "The Determinants of Judicial Prestige and Influence: Some Empirical Evidence from the High Court of Australia." The Journal of Legal Studies 30(1):223-252.

Blackstone, Bethany and Paul M Collins Jr. 2014. "Strategy and the Decision to Dissent on the US Courts of Appeals." Justice System Journal 35(3):269-86.

Caldeira, Gregory, John R Wright and Christopher Zorn. 2012. Organized Interests and Agenda Setting in the US Supreme Court Revisited. In 7th Annual Conference on Empirical Legal Studies Paper.

Calvert, Randall L. 1985. "The Value of Biased Information: A Rational Choice Model of Political Advice." The Journal of Politics 47:530-555.

Cameron, Charles M., Jeffrey A. Segal and Donald R. Songer. 2000. "Strategic Auditing in a Political Hierarchy: An Informational Model of the Supreme Court's Certiorari Decisions." American Political Science Review 94:101-16.

Carrubba, Clifford J. and Tom S. Clark. 2012. "Rule Creation in a Political Hierarchy." American Political Science Review 106(3):622-43.

Chiang, Chun-Fang and Brian Knight. 2011. "Media Bias and Influence: Evidence From Newspaper Endorsements." The Review of Economic Studies 78(3):795-820.

Clark, Tom S. 2009. "A Principal Agent Theory of En Banc Review." Journal of Law, Economics \& Organization 25(1):55-79.

Cross, Frank B. and Emerson H. Tiller. 1998. "Judicial Partisanship and Obedience to Legal Doctrine: Whistleblowing on the Federal Courts of Appeals." Yale Law Journal 107:2155-76.

Epstein, David and Sharyn O'Halloran. 1995. "A Theory of Strategic Oversight: Congress, Lobbyists, and the Bureaucracy." Journal of Law, Economics, Ef Organization 11:227-55.

Gailmard, Sean and John Patty. 2013. "Stovepiping." Journal of Theoretical Politics 25:388411.

Gelman, Andrew and Iain Pardoe. 2007. "Average Predictive Comparisons for Models with Nonlinearity, Interactions, and Variance Components." Sociological Methodology 37(1):23.

George, Tracey E. 1999. "The Dynamics and Determinants of the Decision to Grant En Banc Review." Washington Law Review 74:213-74.

Giles, Micheal W., Thomas G. Walker and Christopher Zorn. 2006. "Setting a Judicial Agenda: The Decision to Grant En Banc Review in the U.S. Courts of Appeals." Journal of Politics 68(4):852-66. 
Giles, Micheal W., Virginia A. Hettinger, Christopher Zorn and Todd C. Peppers. 2007. "The Etiology of the Occurrence of En Banc Review in the U.S. Court of Appeals." American Journal of Political Science 51(3):449-63.

Giles, Micheal W., Virginia A. Hettinger and Todd Peppers. 2001. "Picking Federal Judges: A Note on Policy and Partisan Selection Agendas." Political Research Quarterly 54:623-41.

Gryski, Gerald S. and Gary Zuk. 2008. "A Multi-User Data Base on the Attributes of U.S. Appeals Court Judges, 1801-2000." http://www.cas.sc.edu/poli/juri/auburndata. htm, accessed 15 August 2008.

Gryski, Gerald S., Gary Zuk and Sheldon Goldman. 2008. "A Multi-User Data Base on the Attributes of U.S. District Court Judges, 1789-2000." http://www.cas.sc.edu/poli/ juri/auburndata.htm, accessed 15 August 2008.

Hall, Matthew. 2009. "Experimental Justice: Random Judicial Assignment and the Partisan Process of Supreme Court Review." American Politics Research 37(2):195-226.

Hanmer, Michael J and Kerem Ozan Kalkan. 2013. "Behind the Curve: Clarifying the Best Approach to Calculating Predicted Probabilities and Marginal Effects from Limited Dependent Variable Models." American Journal of Political Science 57(1):263-277.

Hettinger, Virginia A., Stefanie A. Lindquist and Wendy L. Martinek. 2004. "Comparing Attitudinal and Strategic Accounts of Dissenting Behavior on the U.S. Courts of Appeals." American Journal of Political Science 48:123-37.

Hettinger, Virginia A., Stefanie A. Lindquist and Wendy L. Martinek. 2006. Judging on a Collegial Court: Influences on Federal Appellate Decision Making. Charlottesville, VA: University of Virginia Press.

Kastellec, Jonathan P. 2007. "Panel Composition and Judicial Compliance on the U.S. Courts of Appeals." Journal of Law, Economics $\& 5$ Organization 23(2):421-441.

Kastellec, Jonathan P. 2011. "Hierarchical and Collegial Politics on the U.S. Courts of Appeals." Journal of Politics 73(2):345-61.

Kim, Pauline T. 2008. "Deliberation and Strategy on the United States Courts of Appeals: An Empirical Exploration of Panel Effects." University of Pennsylvania Law Review 157:1319-81.

King, Gary, Michael Tomz and Jason Wittenberg. 2000. "Making the Most of Statistical Analyses: Improving Interpretation and Presentation." American Journal of Political Science pp. 347-361.

Klein, David and Darby Morrisroe. 1999. "The Prestige and Influence of Individual Judges on the U.S. Courts of Appeals." The Journal of Legal Studies 28(2):371-391. 
Kuersten, Ashlyn K. and Susan B. Haire. 2007. "Update to the United States Courts of Appeals Database, 1997-2002." available at http://www.as.uky.edu/academics/ departments_programs/PoliticalScience/PoliticalScience/FacultyResources/ Resources/Ulmer/Pages/USCourtsof AppealsDatabase .aspx, accessed 3 June 2008.

Lupia, Arthur and Mathew D. McCubbins. 1994. "Learning from oversight: Fire alarms and police patrols reconstructed." Journal of Law, Economics, \& Organization 10(1):96-125.

Manski, Charles F. and Steven R. Lerman. 1977. "The Estimation of Choice Probabilities from Choice Based Samples." Econometrica 45(8).

McCubbins, Mathew D. and Thomas Schwartz. 1984. "Congressional Oversight Overlooked: Police Patrols versus Fire Alarms." American Journal of Political Science 28(1):165-79.

Note. 1989. "The Politics of En Banc Review." Harvard Law Review 102:864-84.

Oliphant, Robert. 1991. "En Banc Polarization in the Eighth Circuit." Wm. Mitchell L. Rev. 17:701.

Perry, Jr., H.W. 1991. Deciding to Decide: Agenda Setting in the United States Supreme Court. Cambridge: Harvard University Press.

Poole, Keith T. 1998. "Recovering a Basic Space from a Set of Issue Scales." American Journal of Political Science 42:954-93.

Songer, Donald R. 1999. "The United States Courts of Appeals Database, 19251996." available at http://www.as.uky.edu/academics/departments_programs/ PoliticalScience/PoliticalScience/FacultyResources/Resources/Ulmer/Pages/ USCourtsof AppealsDatabase. aspx, accessed 3 June 2008.

Sunstein, Cass R., David Schkade, Lisa M. Ellman and Andres Sawicki. 2006. Are Judges Political? An Empirical Analysis of the Federal Judiciary. Washington, D.C.: Brookings Institution Press.

Tanenhaus, Joseph, Marvin Schick, Matthew Muraskin and Daniel Rosen. 1963. The Supreme Court's Certiorari Decisions: Cue Theory. In Judicial Decision Making, ed. Glendon Schubert. Glencoe, IL: Free Press pp. 111-32.

Ting, Michael M. 2008. "Whistleblowing." American Political Science Review 102(2):249-67.

Van Winkle, Steven. 1997. "Dissent as a Signal: Evidence from the U.S. Courts of Appeals." Presented at the annual meeting of the American Political Science Association. 


\section{Supplemental Appendix}

In this appendix, we:

- explain our case selection procedures;

- describe our weighting and variable creation procedures;

- present a robustness check using an alternative measure of the whistleblower.

\section{Case Selection}

Our dataset comprises two distinct sources of cases that differ according to whether a particular three-judge panel decision was reviewed en banc or not.

Our starting point is the Songer Database, which comprises a random sample of published cases heard in the Courts of Appeals from 1925 to 2002 (Songer 1999, Kuersten and Haire 2007). Specifically, the database samples 30 cases from each circuit for each year. From this sample, we selected each case heard between 1986 and 2002. For each case, we identified the ideological direction of the panel's decision based on the coding procedures in the codebook for the database. If the ideological direction of a case could not be ascertained, we dropped it. We then identified the three judges on the panel; if there was a dissent on the case, we identified which judge on the panel dissented. (We dropped the handful of cases with multiple dissents.)

To increase statistical power, we then augmented this dataset with all cases that were re-heard en banc that we had not already collected. the universe of en banc reviews of threejudge panel decisions made between 1986 and 2002, subject to the constraint that some cases were not included due to missing data or because the ideological direction of the disposition could not be ascertained. We started with the en bancs analyzed in Clark (2009), which covered the 1986 to 1996 period. This dataset identified whether there was a dissent from the three-judge panel decision, but did not identify which judge dissented. We added this information (again dropping a small number of cases with multiple dissents). In a few cases, the panel decision was not available (because it had been withdrawn upon the granting of 
en banc), and we dropped these from our dataset.

Next, we sought to obtain the universe of panel decisions decided from 1997 to 2002 that were reheard en banc. Specifically, we used the following search in Westlaw: SY,DI(BANC \% "BANC DENIED") - this means the search examines both the synopsis of the case and Westlaw's digest of the case. We examined the cases that resulted from this search to determine if they were both actual grants of en banc review and that they originated from a three-judge panel; we did not include cases that went directly from a district court decision to the full circuit. Because votes for rehearing often come a year or two after a panel decision is made, we extended our search through 2004 to capture all potential panel decisions through 2002 that may have been reheard. With these cases in hand, we then added necessary information on the panel decision, the judges in the case, whether there was a dissent, and the general issue in the case (based on the coding of the geniss variable in the Songer database). As above, we excluded cases with no clear ideological direction. Finally, in rare instances, multiple panel decisions will be consolidated into a single en banc review. In these instances we treated each panel decision as a separate observation.

For cases reheard en banc, we then proceeded to code whether the full circuit reversed the three-judge panel's decision. When analyzing a panel decision, it is usually clear whether the panel reverses the lower court, since this information in contained directly in the summary of a case. With en bancs, however, such an approach is not possible, since the full circuit usually withdraws the panel's decision upon the grant of review, and thus it is not clear whether the full circuit is reversing (or upholding) either the district court's decision or the panel decision. Therefore, to generate a reliable and valid measure of reversal, we coded the direction of each en banc decision as either liberal or conservative, using the same coding protocols as used in the Songer database. If the panel made a liberal decision and the full circuit made a conservative decision, we code this as a reversal (and likewise if the panel made a conservative decision and the full circuit made a liberal decision). 
A note about the Ninth Circuit The Ninth Circuit is unique in that uses a "mini enbanc procedure." Instead of all the judges sitting together en banc, a subset of judges from the circuit-specifically the Chief Judge plus 10 additional judges selected at random-is drawn to hear en banc cases. The use of this procedure does not affect our review results, since the subset is not drawn until after the full circuit votes to rehear a case. ${ }^{18}$ With respect to reversal, it is possible that in any given case we have mis-measured the ideal point of the median judge on any given en banc panel, should it differ from the ideal point of the median judge on the full circuit. However, such deviations should cancel out on average, given the random assignment of 10 of the 11 judges on the en banc court, and any measurement error should weaken our results. As a robustness check, we reran the analyses dropping the 9th circuit and the results were unchanged.

\section{Constructing weights}

The result of this procedure is that our data includes all decisions made by three-judge panels between 1986 and 2002 that were ultimately reviewed en banc, plus a stratified random sample of cases that were not reviewed en banc. As such, observations need to be weighted in two ways in order to make proper population-level inferences (Manski and Lerman 1977). First, due to the fact that the Songer database samples cases equally across circuits, circuits with lighter caseloads are overrepresented relative to circuits with higher caseloads. Second, reviewed cases are (greatly) overrepresented relative to non-reviewed cases. For all the analyses that appear in the paper, we constructed weights to account for both types of oversampling. To obtain the total number of cases in the universe, we use the number of published cases (since the Songer database only samples published cases) in each circuit-

\footnotetext{
${ }^{18}$ See p. 142 of the 9 th circuit's rules, available at http://www.ca9.uscourts.gov/rules/: "The en banc court, for each case or group of related cases taken en banc, shall consist of the Chief Judge of this circuit and 10 additional judges to be drawn by lot from the active judges of the Court. In the absence of the Chief Judge, an 11th active judge shall be drawn by lot, and the most senior active judge on the panel shall preside. The drawing of the en banc court will be performed by the Clerk or a deputy clerk of the Court in the presence of at least one judge and shall take place on the first working day following the date of the order taking the case or group of related cases en banc."
} 
year. ${ }^{19}$ Cases that were not reviewed en banc are weighted by the inverse of these population proportions. To account for the oversampling of cases that were reviewed en banc, we need to know the probability of en banc review in the population. We estimate this probability by dividing the number of published cases from that circuit-year that were reviewed $e n$ banc by the total number of decisions published in that circuit-year. We then calculate the proportion of cases in our data that were reviewed en banc for each circuit-year. Cases that were reviewed en banc are weighted by the ratio of these two quantities.

As we note in the text, the analysis of reversal is based on the universe of en banc decisions, so we do not employ weights in these analyses.

\section{Constructing judicial ideology measures}

Information on each judge's appointing president, party of the appointing president, home state and year of appointment was taken from the appeals court judges attribute database (Gryski and Zuk 2008); for district court judges sitting by designation, the same information was taken from the district court judges attribute database (Gryski, Zuk and Goldman 2008). In some cases, either a judge from the Federal Circuit or a non-Article III judge (for example, one from the U.S. Court of International Trade) sat on a threejudge panel. We used the biographical database of the Federal Judicial Center, available at http://www.fjc.gov/public/home.nsf/hisj, to identify the judge's appointing president and the president's party.

The measure of judicial ideology used in the regression analyses are the scores created by Giles, Hettinger and Peppers (2001). They involve using the Common Space scores (that is, ideal point estimates of the President and members of Congress that are comparable across time and branches) of the appointing president and/or a nominee's home state senators (Poole 1998). The procedure is the same for all appeals court judges and district court judges.

\footnotetext{
${ }^{19}$ This measure was provided to us by Stefanie Lindquist, and comes from caseload data from the Administrative Office of the U.S. Courts.
} 
The first step is to determine whether senatorial courtesy is in effect. Following Giles, Hettinger and Peppers (2001), we assume that senatorial courtesy exists whenever one senator from a nominee's home state is of the same party as the president. If one (and only one) senator is of the same party, then the GHP score takes on that senator's Common Space score. If both senators are of the home state party, the GHP score is average of their Common Space scores. If neither senator is of the president's party, the GHP score takes on the president's Common Space score. We assume that senatorial courtesy is not in effect for judges appointed to the D.C. Circuit, judges who come from U.S. territories, all non-Article III judges. Thus, for these judges, their GHP scores is the common space score of their appointing president.

For each judge we coded their appointing president's Common Space score, the Common Space scores of the judge's home state senators, and whether senatorial courtesy was in effect during the judge's nomination. In some cases, more than two senators served during the Congress in which a nominee was appointed. Using the "Biographical Directory of the United States Congress," we determined which two senators were in office at the time of the judge's nomination. (The directory can be accessed at http://bioguide.congress.gov/ biosearch/biosearch.asp.) We then created GHP scores using the above criteria.

To obtain the ideology of the full circuit for our analyses, for each circuit and each year from 1986 to 2002, we collected the name and party of the appointing president of every active judge from the biographical database of the Federal Judicial Center, available at http://www.fjc.gov/public/home.nsf/hisj. We counted a judge as being active in a given year if he or she served at least six months in that year. Senior judges were not included. For example, if a judge took senior status in May 2003, she was not counted as having been active in 2003. We then calculated the GHP score of each active judge on a circuit, and then calculated the median score in a given year. 


\section{Analysis using alternative measure of the whistleblower}

While the robustness checks presented in the paper support our theoretical claims, a potential objection is that the analysis assumes that the same judge serves as the whistleblower, regardless of whether the panel makes a liberal or a conservative decision. Of course, this may not be the case - on a three-judge panel, the whistleblower may vary depending on the decision the panel reaches. For example, when the panel is more liberal than the circuit, we identify the whistleblower as the most conservative judge on the panel. But when the panel makes a conservative decision, this judge is in fact most favorably disposed to the panel's disposition, so one might expect the most liberal judge to be the whistleblower, given that is the judge least disposed to the disposition. This expectation is based simply on the interaction between judges' preferences and the panel's decision, and is thus independent of the location of the circuit.

An alternative measure of the whistleblower, derived from votes, captures this possibility using the following operationalization: define the whistleblower as the most liberal judge if the panel disposition is conservative, and the most conservative judge if the panel disposition is liberal. ${ }^{20}$ The downside of this measure is that it is endogenous to the votes in the case, whereas our preference-based measure is not. Note, however, that in suspicious decisions with dissent, the two measures will lead to identical codings of the variable whistleblower dissent, and thus the key difference comes when evaluating non-suspicious decisions.

Our theory predicts that dissents from such decisions should not trigger en banc review. Again, this is not always true empirically, as some dissents by these judges do generate review. But, just as with the preference-based measure of the potential whistleblower, dissents by "votes-based" whistleblowers should not trigger review in non-suspicious decisions in a manner consistent with the predictions about counter-preference signals and panel-circuit distance.

\footnotetext{
${ }^{20}$ Note this does not assume the potential whistleblower disagrees with the disposition, just that he will get less spatial utility than his colleagues, given the utility function in the model, which is a function of the distance between a judge's indifference points and the case facts.
} 


\begin{tabular}{|c|c|c|c|}
\hline & (1) & (2) & (3) \\
\hline Intercept & $\begin{array}{r}-5.37^{*} \\
(0.18)\end{array}$ & $\begin{array}{r}-6.29^{*} \\
(0.21)\end{array}$ & $\begin{array}{r}-6.02 \\
(0.40)\end{array}$ \\
\hline Whistleblower dissent & $\begin{array}{c}2.19 \\
(0.42)\end{array}$ & $\begin{array}{c}2.77 \\
(0.43)\end{array}$ & $\begin{array}{c}2.83 \\
(0.45)\end{array}$ \\
\hline Suspicious decisions & $\begin{array}{c}0.06 \\
(0.22)\end{array}$ & $\begin{array}{c}0.19 \\
(0.24)\end{array}$ & $\begin{array}{c}0.26 \\
(0.24)\end{array}$ \\
\hline Panel-whistleblower $(P-W)$ distance & $\begin{array}{c}-0.43 \\
(0.47)\end{array}$ & $\begin{array}{c}0.14 \\
(0.53)\end{array}$ & $\begin{array}{c}-0.08 \\
(0.55)\end{array}$ \\
\hline Panel-circuit $(P-C)$ distance & $\begin{array}{c}0.11 \\
(0.49)\end{array}$ & $\begin{array}{c}0.46 \\
(0.49)\end{array}$ & $\begin{array}{c}0.07 \\
(0.49)\end{array}$ \\
\hline Suspicious decision $\times(P-W)$ distance & $\begin{array}{c}-0.46 \\
(0.53)\end{array}$ & $\begin{array}{c}-0.87 \\
(0.60)\end{array}$ & $\begin{array}{c}-0.78 \\
(0.61)\end{array}$ \\
\hline Suspicious decision $\times(P-C)$ distance & $\begin{array}{c}2.65 \\
(0.56)\end{array}$ & $\begin{array}{c}2.32 \\
(0.58)\end{array}$ & $\begin{array}{c}2.40 \\
(0.59)\end{array}$ \\
\hline Whistleblower dissent $\times$ suspicious decision & $\begin{array}{c}0.64 \\
(0.54)\end{array}$ & $\begin{array}{c}0.40 \\
(0.54)\end{array}$ & $\begin{array}{c}0.62 \\
(0.56)\end{array}$ \\
\hline Whistleblower dissent $\times(P-W)$ distance & $\begin{array}{c}0.02 \\
(1.27)\end{array}$ & $\begin{array}{c}-0.76 \\
(1.28)\end{array}$ & $\begin{array}{c}-1.17 \\
(1.33)\end{array}$ \\
\hline Whistleblower dissent $\times(P-C)$ distance & $\begin{array}{c}-0.71 \\
(0.97)\end{array}$ & $\begin{array}{c}-0.86 \\
(0.97)\end{array}$ & $\begin{array}{r}-0.99 \\
(0.95)\end{array}$ \\
\hline Whistleblower dissent $\times$ suspicious decision $\times P-W$ distance & $\begin{array}{l}-1.23 \\
(1.42)\end{array}$ & $\begin{array}{c}-0.51 \\
(1.44)\end{array}$ & $\begin{array}{r}-0.50 \\
(1.49)\end{array}$ \\
\hline Whistleblower dissent $\times$ suspicious decision $\times P-C$ distance & $\begin{array}{l}1.23 \\
(1.17)\end{array}$ & $\begin{array}{l}1.28 \\
(1.19)\end{array}$ & $\begin{array}{c}1.69 \\
(1.17)\end{array}$ \\
\hline Non-whistleblower dissent & & $\begin{array}{c}2.52 \\
(0.14)\end{array}$ & $\begin{array}{c}2.64 \\
(0.15)\end{array}$ \\
\hline Panel reversed lower court & & $\begin{array}{c}0.75 \\
(0.11)\end{array}$ & $\begin{array}{c}0.78 \\
(0.11)\end{array}$ \\
\hline$N$ & 5589 & 5589 & 5589 \\
\hline AIC & 126.44 & 129.98 & 190.94 \\
\hline
\end{tabular}

Table A-1: Regression models of review, using the votes-based measure of the potential whistleblower. The inputs of the model are the same as in Table 2 in the paper. Each model is a weighted logit. Standard errors in parentheses. Fixed effect for circuits, years, and issues are estimated in Model 3, but not displayed.

Table A-1 presents three regression models of en banc review that parallel Models 1-3 in Table 2 of the paper, except that we use the alternative measure to create the preferences of $W$. We then define panel-whistleblower distance as the absolute value of the distance between the panel median and the whistleblower. We use Model 2 in this table to generate Figures A-1A and A-1B, which parallel the results in Figure 5C and Figure 5D in the paper, respectively. Again, we see that both distances play no role in the probability of review. Thus, even when we define the whistleblower in terms of votes, the probability of review of non-suspicious decisions does not vary in the location of the panel or the whistleblower, consistent with the predictions of the model. Taken together, we are confident that our theory and empirical approach is capturing the way in which dissents interact with preferences in the judicial hierarchy. 

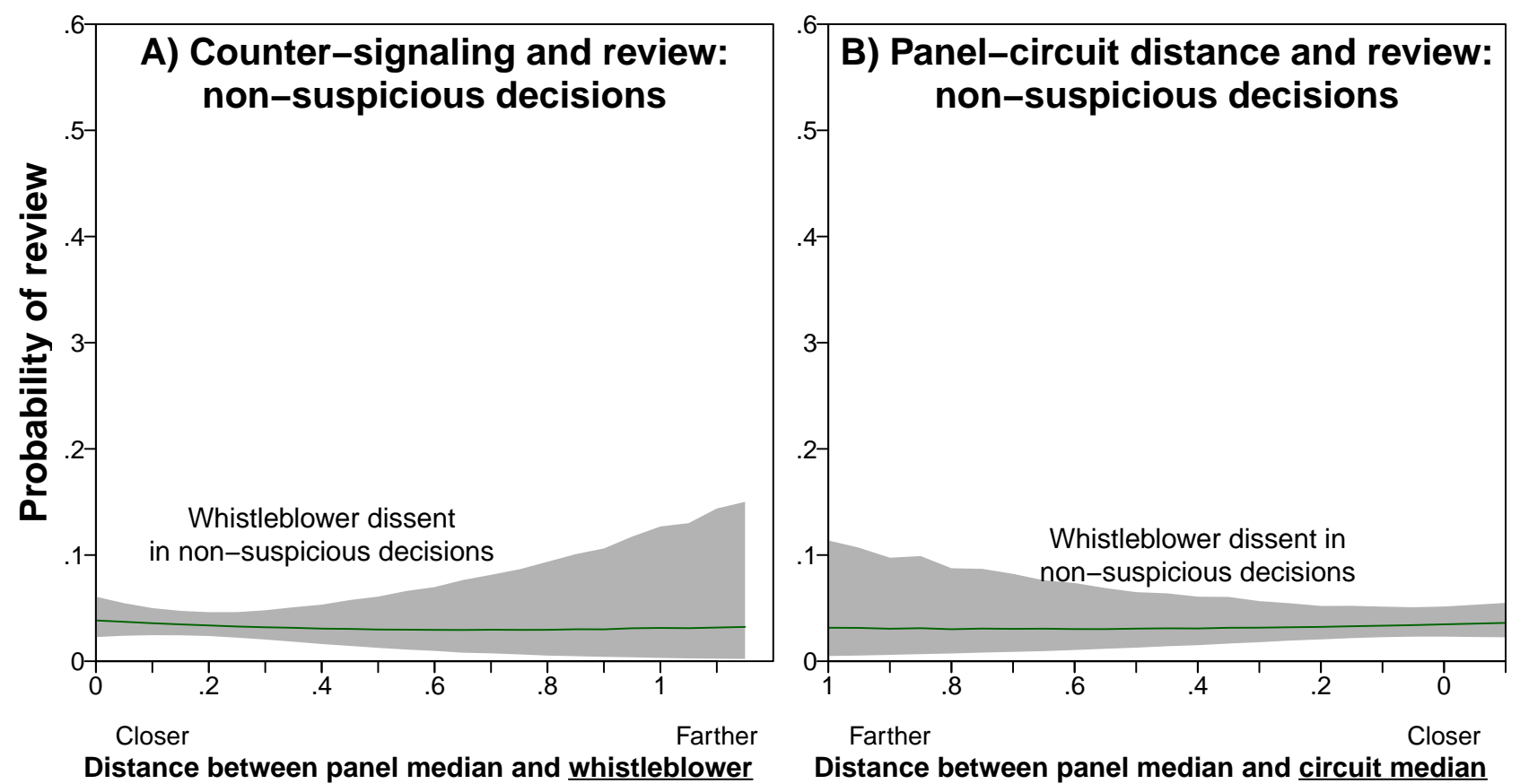

Distance between panel median and whistleblower

Distance between panel median and circuit median

Figure A-1: Predicted probabilities of en banc review in non-suspicious decisions, using an alternative measure of the whistleblower. A) How the probability of review changes as the distance between the panel median and whistleblower increases, in non-suspicious decisions with whistleblower dissents. B) How the probability of review changes as the distance between the panel median and circuit median decreases, in non-suspicious decisions with whistleblower dissents. Results based on Model 2 in Table A-1. 